\title{
A little frog leaps a long way: Compounded colonizations of the Indian Subcontinent discovered in the tiny Oriental frog genus Microhyla (Amphibia: Microhylidae)
}

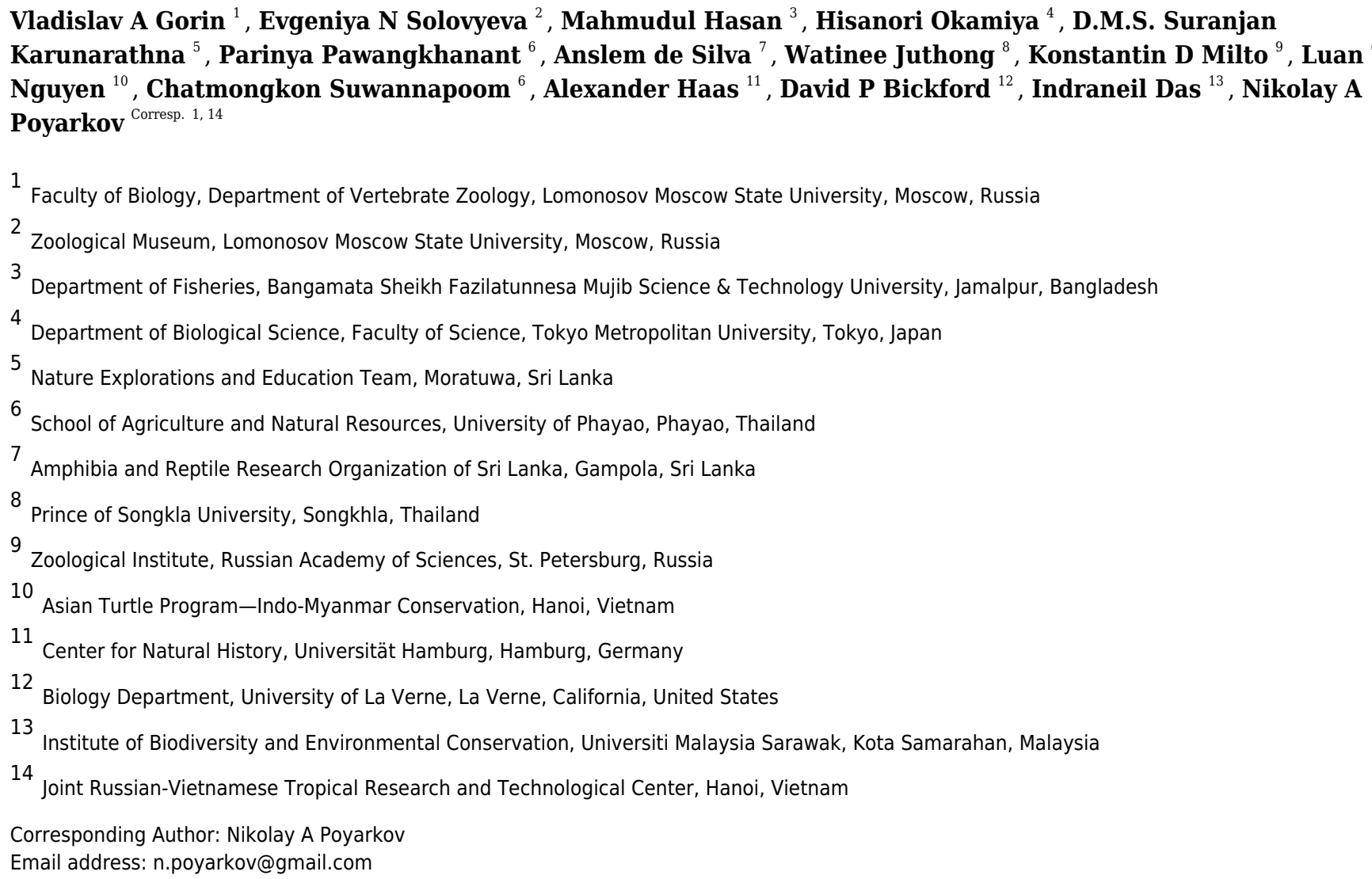

Frogs of the genus Microhyla include some of the world's smallest amphibians and represent the largest radiation of Asian microhylids, currently encompassing 50 species, distributed across the Oriental biogeographic region. The small-sized genus Microhyla remains one of the taxonomically most challenging groups of Asian frogs and was found to be paraphyletic with respect to large-sized fossorial Glyphoglossus. In this study we present a time-calibrated phylogeny for frogs in the genus Microhyla, and discuss taxonomy, historical biogeography, and morphological evolution of these frogs. Our updated phylogeny of the genus with nearly complete taxon sampling includes 48 nominal Microhyla species and several undescribed candidate species. Phylogenetic analyses of $3207 \mathrm{bp}$ of both mtDNA and nuDNA data recovered three well-supported groups: the Glyphoglossus clade, Southeast Asian Microhyla II clade (includes M. annectens species group), and a diverse Microhyla I clade including all other species. Within the largest major clade of Microhyla are seven well-supported subclades, that we identify as the M. achatina, 
M. fissipes, M. berdmorei, M. superciliaris, M. ornata, M. butleri, and M. palmipes species groups. The phylogenetic position of 12 poorly known Microhyla species is clarified for the first time. These phylogenetic results, along with molecular clock and ancestral area analyses, show the Microhyla - Glyphoglossus assemblage to have originated in Southeast Asia in the middle Eocene just after the first hypothesized land connections between the Indian Plate and the Asian mainland. While Glyphoglossus and Microhyla II remained within their ancestral ranges, Microhyla I expanded its distribution generally east to west, colonizing and diversifying through the Cenozoic. The Indian Subcontinent was colonized by members of five Microhyla species groups independently, starting with the end Oligocene - early Miocene that coincides with an onset of seasonally dry climates in South Asia. Body size evolution modeling suggests that four groups of Microhyla have independently achieved extreme miniaturization with adult body size below $15 \mathrm{~mm}$. Three of the five smallest Microhyla species are obligate phytotelm-breeders and we argue that their peculiar reproductive biology may be a factor involved in miniaturization. Body size increases in Microhyla - Glyphoglossus seem to be associated with a burrowing adaptation to seasonally dry habitats. Species delimitation analyses suggest a vast underestimation of species richness and diversity in Microhyla and reveal 15 to 33 undescribed species. We revalidate $M$. nepenthicola, synonymize $M$. pulverata with $M$. marmorata, and provide insights on taxonomic statuses of a number of poorly known species. Further integrative studies, combining evidence from phylogeny, morphology, advertisement calls, and behavior will result in a better systematic understanding of this morphologically cryptic radiation of Asian frogs. 
1 A little frog leaps a long way: Compounded colonizations of the

2 Indian Subcontinent discovered in the tiny Oriental frog genus

3 Microhyla (Amphibia: Microhylidae)

4

5

6 Vladislav A. Gorin ${ }^{1}$, Evgeniya N. Solovyeva ${ }^{2}$, Mahmudul Hasan ${ }^{3}$, Hisanori Okamiya ${ }^{4}$, 7

\section{D.M.S. Suranjan Karunarathna ${ }^{5}$, Parinya Pawangkhanant ${ }^{6}$, Anslem de Silva ${ }^{7}$, Watinee} Juthong8, Konstantin D. Milto9, Luan Thanh Nguyen'10, Chatmongkon Suwannapoom ${ }^{6}$, Alexander Haas ${ }^{11}$, David P. Bickford ${ }^{12}$, Indraneil Das ${ }^{13}$, Nikolay A. Poyarkov ${ }^{1,14 *}$

1 - Faculty of Biology, Department of Vertebrate Zoology, Lomonosov Moscow State University, Moscow, Russia

2 - Zoological Museum, Lomonosov Moscow State University, Moscow, Russia

3 - Department of Fisheries, Bangamata Sheikh Fazilatunnesa Mujib Science \& Technology University, Jamalpur, Bangladesh

4 -Department of Biological Science, Faculty of Science, Tokyo Metropolitan University, Tokyo, Japan

5 - Nature Explorations and Education Team, Moratuwa, Sri Lanka

6 - School of Agriculture and Natural Resources, University of Phayao, Phayao, Thailand

7 - Amphibia and Reptile Research Organization of Sri Lanka, Gampola, Sri Lanka.

8 - Prince of Songkla University, Songkhla, Thailand

9 - Zoological Institute, Russian Academy of Sciences, St. Petersburg, Russia

10 - Asian Turtle Program-Indo-Myanmar Conservation, Hanoi, Vietnam

11 - Universität Hamburg, Center for Natural History, Hamburg, Germany

12 - Biology Department, University of La Verne, La Verne, California, USA

13 - Institute of Biodiversity and Environmental Conservation, Universiti Malaysia Sarawak, Kota Samarahan, Malaysia

14 - Joint Russian-Vietnamese Tropical Research and Technological Center, Hanoi, Vietnam

* -corresponding author; E-mail:n.poyarkov@gmail.com 
30

31

32

33

\section{Abstract}

Frogs of the genus Microhyla include some of the world's smallest amphibians and represent the largest radiation of Asian microhylids, currently encompassing 50 species, distributed across the Oriental biogeographic region. The small-sized genus Microhyla remains one of the taxonomically most challenging groups of Asian frogs and was found to be paraphyletic with respect to large-sized fossorial Glyphoglossus. In this study we present a time-calibrated phylogeny for frogs in the genus Microhyla, and discuss taxonomy, historical biogeography, and morphological evolution of these frogs. Our updated phylogeny of the genus with nearly complete taxon sampling includes 48 nominal Microhyla species and several undescribed candidate species. Phylogenetic analyses of $3207 \mathrm{bp}$ of both mtDNA and nuDNA data recovered three well-supported groups: the Glyphoglossus clade, Southeast Asian Microhyla II clade (includes M. annectens species group), and a diverse Microhyla I clade including all other species. Within the largest major clade of Microhyla are seven well-supported subclades, that we identify as the M. achatina, M. fissipes, M. berdmorei, M. superciliaris, M. ornata, M. butleri, and M. palmipes species groups. The phylogenetic position of 12 poorly known Microhyla species is clarified for the first time. These phylogenetic results, along with molecular clock and ancestral area analyses, show the Microhyla - Glyphoglossus assemblage to have originated in Southeast Asia in the middle Eocene just after the first hypothesized land connections between the Indian Plate and the Asian mainland. While Glyphoglossus and Microhyla II remained within their ancestral ranges, Microhyla I expanded its distribution generally east to west, colonizing and diversifying through the Cenozoic. The Indian Subcontinent was colonized by members of five Microhyla species groups independently, starting with the end Oligocene - early Miocene that coincides with an onset of seasonally dry climates in South Asia. Body size evolution modeling suggests that four groups of Microhyla have independently achieved extreme miniaturization with adult body size below $15 \mathrm{~mm}$. Three of the five smallest Microhyla species are obligate phytotelm-breeders and we argue that their peculiar reproductive biology may be a factor involved in miniaturization. Body size increases in Microhyla - Glyphoglossus seem to be associated with a burrowing adaptation to seasonally dry habitats. Species delimitation analyses suggest a vast underestimation of species richness and diversity in Microhyla and reveal 15 to 33 undescribed species. We revalidate $M$. nepenthicola, synonymize $M$. pulverata with $M$. marmorata, and provide insights on taxonomic statuses of a number of poorly known species. 
61 Further integrative studies, combining evidence from phylogeny, morphology, advertisement 62 calls, and behavior will result in a better systematic understanding of this morphologically cryptic radiation of Asian frogs.

Subjects: Biodiversity, Biogeography, Evolutionary Studies, Taxonomy, Zoology

Keywords: molecular phylogeny, biogeography, miniaturization, Narrow-mouthed frogs, Southeast Asia, Microhylinae, species delimitation, Indian collision, cryptic species, Glyphoglossus

\section{Introduction}

The tropical areas of South and Southeast Asia include biogeographic regions recognized as global centers of biodiversity (Myers et al., 2000; Bain et al., 2008; Stuart, 2008; De Bruyn et $a l ., 2014)$. Understanding processes that sculpted this diversity is hampered by a highly complex geological and climatic history of this region. Combining data on tectonics, paleoclimate, and phylogenetics has proved to be a powerful instrument for examining patterns of diversification within clades and understanding processes involved in the assembly of high biodiversity in regions like South and Southeast Asia (e.g. De Bruyn et al., 2014).

The tectonic collision between the Indian subcontinent (ISC) and the Eurasian landmass during the Early Cenozoic is widely recognized as a key event that caused significant geologic and climatic changes, such as the rise of the Himalaya, uplift of the Tibetan plateau, and a general drying of Central Asia (Harrison et al., 1992; An et al., 2001; Guo et al., 2002; Molnar, 2005; Solovyeva et al., 2018). This tectonic event also induced a major biotic interchange between the ISC and Eurasia and is widely regarded as a major driver of biotic diversification (Wilkinson et al., 2002; Roelants et al., 2004; Li et al., 2013; Garg \& Biju, 2019). Numerous studies have demonstrated that floral and faunal elements reached and colonized tropical Asia from Gondwanaland via the northward drifting ISC (Dayanandan et al., 1999; Klaus et al., 2010, 2016; Kamei et al., 2012; Morley, 2018), the so called "out-of-India" hypothesis (Bossuyt \& Milinkovitch, 2001; Conti et al., 2002; Gower et al., 2002; Biju \& Bossuyt, 2003; Sparks, 2003; Dutta et al., 2004; Karanth, 2006; Datta-Roy \& Karanth, 2009). At the same time, a set of phylogenetic studies of different animal groups proposed an alternative "out-of-Eurasia" biogeographic hypothesis, suggesting a Southeast Asian origin of these lineages with further dispersal and colonization of the ISC during its collision with the Eurasian landmass (Raxworthy 
92 et al., 2002; Renner, 2004; Köhler \& Glaubrecht, 2007; Van der Meijden et al., 2007; Macey et 93 al., 2008; Grismer et al., 2016; Garg \& Biju, 2019).

94

95

96

97

98

100

101

102

103

104

105

106

107

108

109

110

111

112

113

114

115

116

117

118

119

120

121

122

There is an ongoing debate on timing and topography of the ISC-Eurasian collision (Acton, 1999; Van Hinsbergen et al., 2011, 2012; Ali \& Aitchison, 2008, 2012). Some recent geologic models suggest land bridges connected ISC and modern Southeast Asia since the early Eocene (ca. 55-35 MYA), well before collision of the Indian plate with Eurasia (30-25 MYA) (Aitchison et al., 2007; Aitchison \& Ali, 2012; Hall, 2012; Ding et al., 2017). Several phylogenetic studies corroborate the existence of pre-collision faunal exchanges between the ISC and Southeast Asia, demonstrating that they likely went in both directions: "out-of-India" and “out-of-Eurasia” (Klaus et al., 2010; Li et al., 2013; Grismer et al., 2016; Garg \& Biju, 2019). Overall, the impact of the "out-of-India" or "out-of-Eurasia" biogeographic scenarios in precollision or post-collision biotic exchanges between the ISC and the Asian mainland remains insufficiently studied and unresolved.

Frogs of the family Microhylidae are some of the most species rich groups of Anura, comprising 690 species in 12 subfamilies (Frost, 2020; Streicher et al., 2020). Because of their transcontinental circumtropical distribution, microhylids are a promising test case for biogeography studies (Savage, 1973; Van Bocxlaer et al., 2006; Van der Meijden et al., 2007; Kurabayashi et al., 2011). Among the 12 currently recognized subfamilies of microhylids, the subfamily Microhylinae is widely distributed in South, Southeast, and East Asia currently including eight genera with nearly one hundred species (Garg \& Biju, 2019; Frost, 2020). Their phylogenetic relationships and historical biogeography have been discussed in several studies (Van Bocxlaer et al., 2006; Frost et al., 2006; Matsui et al., 2011; de Sá et al., 2012; Peloso et al., 2016; Feng et al., 2017). The most recent analysis of genus-level phylogeny within the Microhylinae by Garg \& Biju (2019) suggested their origin on the ISC during early Paleocene with dispersal to the Asian mainland via several Eocene land bridges connecting the ISC with Southeast Asia. Following accretion of India and Eurasia in the Oligocene/Miocene, some Microhylinae lineages that diversified in Southeast Asia could have recolonized the ISC (Garg \& Biju, 2019). However, phylogenetic relationships and historical biogeography within Microhylinae genera remain poorly resolved.

The genus Microhyla is the most species rich genus in the Microhylinae, currently comprising 50 recognized species (Poyarkov et al., 2014, 2019; Biju et al., 2019). Over half of 
123 this diversity has been described within the last 15 years (27 species, see Frost, 2020), yet 124 Microhyla remains one of the most taxonomically challenging groups of Asian frogs. Most 125 species of Microhyla are small-sized terrestrial frogs, while several diminutive species approach 126 the lower body-size limit for vertebrates and represent some of the world's tiniest amphibians 127 (Das \& Haas, 2010; Poyarkov et al., 2014). In miniaturized groups of amphibians, a high 128 proportion of cryptic diversity and rampant homoplasies are often recorded, obscuring our estimates of diversity and evolutionary relationships (e.g., Hanken \& Wake, 1993; Rovito et al., 2013; Parra-Olea et al., 2016; Rakotoarison et al., 2017). Molecular phylogenetic analyses, optimally combined with behavioral and acoustic data, offer the best hope for clarifying diversity, species boundaries, and evolutionary relationships in many groups of Microhylidae, including the genus Microhyla (Hasan et al., 2014a; Garg et al., 2019; Poyarkov et al., 2018a, 2019).

Despite significant progress in our understanding of Microhyla diversity in recent years, hypothesizing evolutionary origins of the genus remains a challenging task. Microhyla is the only Asian microhylid genus with a wide distribution over South, Southeast, and East Asia (see Fig. 1), making it an ideal model for studies on Asian biogeography. Phylogenetic relationships among members of the genus Microhyla have been discussed in several recent studies (Matsui et al., 2011; Peloso et al., 2016; Tu et al., 2018; Nguyen et al., 2019; Biju et al., 2019); however, they were generally based on limited sampling ( $<60 \%$ of recognized diversity). Monophyly of Microhyla was questioned by Matsui et al. (2011), based on analysis of mitochondrial DNA (mtDNA) markers, but later corroborated by multi-locus phylogenetic analyses (Peloso et al., 2016; Tu et al., 2018). Only a few works have provided insights on biogeographic origin, patterns of distribution, and possible routes of colonization for the genus (Vineeth et al., 2018; Garg et al., 2019; Poyarkov et al., 2019). Though the greatest species diversity of Microhyla is observed in Southeast Asia (up to nine sympatric species in Indochina, see Fig. 1), some studies suggested the possibility of an Indian origin for the genus and several species groups (Garg et al., 2019; Garg \& Biju, 2019). That may be explained by biased taxonomic and geographic representation of Microhyla species in these works, primarily focused on South Asian taxa. Extensive taxon sampling of all known members of the genus Microhyla, including molecularly previously unstudied taxa from Southeast Asia, a more robustly resolved phylogeny, and sound divergence age estimates are important to understand historical distribution and diversification in 
153 this radiation of Asian frogs (Garg et al., 2019). Thus far, however, a comprehensive

154 phylogenetic investigation with dating estimates within the genus Microhyla is lacking.

155 Herein, we identify unrecognized diversity and examine phylogenetic relationships

156 among almost all described species of Microhyla based on extensive geographic and taxonomic

157 sampling, including 48 of 50 nominal species (96\% of recognized taxa); phylogenetic

158 information for 12 species and a number of candidate new species is reported for the first time.

159 We use the resulting phylogeny (based on both mtDNA and nuDNA markers) to test

160 biogeographic hypotheses in space and time and provide a scenario for Microhyla diversification.

161 Our study provides the first nearly complete phylogeny for the genus Microhyla and links the

162 Indian Subcontinent with Sundaland, Indo-Burma, and East Asia, thereby allowing a better

163 understanding of biogeographic history and diversification of the group. We also evaluate

164 miniaturization and simulate body size evolution across different lineages of the genus,

165 providing novel insights into morphological evolution in Microhyla.

\section{Materials and methods}

Taxon sampling

We used tissues from the herpetological collections of Zoological Museum of Moscow University (ZMMU; Moscow, Russia); Zoological Institute, Russian Academy of Sciences (ZISP; St. Petersburg, Russia); Vertebrate Zoology Department, Biological Faculty, Moscow State University (ZPMSU; Moscow, Russia); Amphibian Research Center, Hiroshima University (IABHU; Higashihiroshima, Japan); Danum Valley Conservation Area, Specimen collection

174 (RMBR; Sabah, Malaysia); Department of Fisheries, Bangamata Sheikh Fazilatunnesa Mujib

175 Science \& Technology University (DFBSFMSTU; Jamalpur, Bangladesh); School of Agriculture and Natural Resources, University of Phayao (AUP; Phayao, Thailand); and the Institute of

177 Biodiversity and Environmental Conservation, Universiti Malaysia Sarawak, (UNIMAS;

178 Sarawak, Malaysia) (information summarized in Table S1). Permissions to conduct fieldwork and collect specimens were granted by the Institutional Ethical Committee of Animal 180 Experimentation of University of Phayao (permit number 610104022), the Institute of Animals for Scientific Purpose Development (IAD), Bangkok, Thailand (permit number U1-01205-2558), 
184 number WL/3/2/1/14/12), the Forest Protection Departments of the Peoples' Committee of Gia 185 Lai Province (permit number \#530/UBND-NC), the Department of Forestry, Ministry of 186 Agriculture and Rural Development of Vietnam (permit numbers \#142/SNgV-VP, \#1539/TCLN187 DDPH, \#1700/UBND.VX and \#308/SNgV-LS).

188 We analyzed 122 tissue samples representing 40 nominal species of Microhyla, 14 189 species have not been included in previous phylogenetic analyses. In our analysis, we also 190 included GenBank sequences from 78 specimens of approximately 37 nominal Microhyla 191 species, 29 other Microhylidae representatives, and five non-microhylid outgroups used for 192 rooting the phylogenetic tree and divergence times estimation (Table S1). In total, we obtained 193 molecular genetic data for 199 samples representing 48 nominal Microhyla species. Geographic 194 location of sampled populations is presented in Fig. S1. For alcohol-preserved voucher 195 196 specimens stored in museum collections, we removed a small sub-sample of muscle, preserved it in $96 \%$ ethanol, and stored samples at $-70^{\circ} \mathrm{C}$.

\section{DNA extraction, amplification and sequencing}

For molecular phylogenetic analyses, total genomic DNA was extracted from ethanolpreserved femoral muscle tissue using standard phenol-chloroform-proteinase $\mathrm{K}$ (final concentration $1 \mathrm{mg} / \mathrm{ml}$ ) extraction procedures with consequent isopropanol precipitation (protocols followed Sambrook \& Russell, 2001; Swofford et al., 1996).

For mtDNA, we amplified sequences covering fragments of 12S rRNA, tRNAVal, and 16S rRNA mtDNA genes to obtain an up to $2478 \mathrm{bp}$-length continuous fragment of mtDNA. The 16S rRNA gene has been widely applied in biodiversity surveys in amphibians (Vences et al., 2005; Vieites et al., 2009) and 12S rRNA + 16S rRNA data have been used in several important studies on Microhylinae phylogeny (Matsui et al. 2011; Peloso et al. 2016). These fragments have also proven to be particularly useful in taxonomic studies of the genus Microhyla and closely-related taxa (e.g. Hasan et al., 2012, 2014a, 2014b; Howlader et al., 2015; Matsui, 2011; Matsui et al., 2011, 2013; Wijayathilaka et al., 2016).

For nuDNA, we amplified a 729 bp-long fragment of brain-derived neurotrophic factor gene $(B D N F)$. This marker was recently successfully applied in biodiversity and phylogenetic studies of Indian Microhyla species (see Garg et al., 2019; Garg \& Biju, 2019; Biju et al., 2019).

213 Primers used in PCR and sequencing were taken from the literature or designed by us and 214 summarized in Table S2. 

step of $5 \mathrm{~min}$ at $94^{\circ} \mathrm{C}$, and 40 cycles of denaturation for $1 \mathrm{~min}$ at $94^{\circ} \mathrm{C}$, primer annealing step for

$2171 \mathrm{~min}$ with TouchDown program from $65^{\circ} \mathrm{C}$ reducing $1{ }^{\circ} \mathrm{C}$ every cycle to $55^{\circ} \mathrm{C}$, and extension 218 step for $1 \mathrm{~min}$ at $72^{\circ} \mathrm{C}$, and the final extension step for $5 \mathrm{~min}$ at $72^{\circ} \mathrm{C}$. The PCR conditions for 219 amplifying BDNF gene followed Van der Meijden et al. (2007) and included an initial 220 denaturation step of $5 \mathrm{~min}$ at $94^{\circ} \mathrm{C}$ followed with 32 cycles of denaturation for $1 \mathrm{~min}$ at $94^{\circ} \mathrm{C}$, 221 primer annealing step for $1 \mathrm{~min}$ at $50^{\circ} \mathrm{C}$, and extension for $1 \mathrm{~min}$ at $72^{\circ} \mathrm{C}$, with final extension 222 step for $5 \mathrm{~min}$ at $72^{\circ} \mathrm{C}$. PCRs were run on an Bio-Rad T100 ${ }^{\mathrm{TM}}$ Thermal Cycler; sequence data collection and visualization were performed on an ABI 3730xl automated sequencer (Applied Biosystems). PCR purification and cycle sequencing were done commercially through Evrogen ${ }^{\circledR}$ (Moscow, Russia). All unique sequences were deposited in GenBank (see Table S1).

\section{Phylogenetic analyses}

227

In addition to newly obtained sequences, we also used 107 DNA sequences of

Microhylidae from GenBank in our final alignments; sequences of Rhacophorus schlegelii, Alytes dickhilleni, A. muletensis, Blommersia transmarina and B. wittei were selected as outgroup taxa to help root our tree and were also used for time-tree calibration. Details on taxonomy, localities, GenBank accession numbers, and associated references for all examined specimens are summarized in Table S1.

Nucleotide sequences were initially aligned in MAFFT v6 (Katoh et al., 2002) with default parameters, subsequently checked by eye in BioEdit v7.0.5.2 (Hall, 1999), and adjusted as needed.

We reconstructed phylogenetic trees with two datasets:

(1) A mtDNA dataset joining 12S rRNA and 16S rRNA for all examined samples, used for assessment of species groups and estimation of cryptic diversity within Microhyla (230 sequences, including 199 sequences of Microhyla);

(2) A concatenated mtDNA + nuDNA dataset, joining long 12S rRNA - 16S rRNA mtDNA fragment and $B D N F$ gene sequences for 118 selected samples representing all major Microhyla. 
The optimum partitioning schemes for alignments were identified with PartitionFinder

246

247

248

249

250

251

252

253

254

255

256

257

258

259

260

261

262

263

264

265

266

267

268

269

270

271

272

273

274

2.1.1 (Lanfear et al., 2012) using the greedy search algorithm under an AIC criterion, and are presented in Table S3. Phylogenies were hypothesized via maximum likelihood (ML) and Bayesian Inference (BI). We used IQ-TREE (Nguyen et al., 2015) to reconstruct ML phylogenies. Confidence in tree topology for ML analysis was assessed by 1000 bootstrap replications for ML analysis (ML BS). Bayesian inference (BI) was performed in MrBayes v3.1.2 (Ronquist \& Huelsenbeck, 2003) with two simultaneous runs, each with four chains for 200 million generations. We checked that the effective sample sizes (ESS) were all above 200 by exploring likelihood plots using TRACER v1.6 (Rambaut \& Drummond, 2007). The initial 10\% of trees were discarded as burn-in. Confidence in tree topology was assessed by posterior probability for Bayesian analysis (BI PP) (Huelsenbeck \& Ronquist, 2001). We a priori regarded tree nodes with ML BS values $75 \%$ or greater and BI PP values over 0.95 as sufficiently resolved (Huelsenbeck \& Hillis, 1993; Felsenstein, 2004). For clarity, ML BS values between 75\% and 50\% (BI PP between 0.95 and 0.90) were regarded as tendencies and below 50\% (BI PP below 0.90) were considered unresolved. The allele network for the $B D N F$ gene was constructed using median-joining method in the PopArt v1.5 (Leigh \& Bryant, 2015) with 95\% connection limit.

\section{Species delimitation}

We examined putative species boundaries beyond those currently recognized by taxonomists based on two different species delimitation methods: The Automatic Barcode Gap Discovery (ABGD; Puillandre et al., 2012) and the Generalized Mixed Yule-Coalescent model (GMYC; Pons et al., 2006). These methods enable the delimitation of independently-evolving species based on genetic data (Fujita et al., 2012; Dellicour \& Flot, 2015; Eyer et al., 2017) and do not require a priori hypotheses of putative species groupings, thereby limiting potential bias in species delimitation.

The ABGD method is a single-gene approach to statistical detection of barcode gaps in a pairwise genetic distance distribution (Puillandre et al., 2012). Barcode gaps, presumably occurring between intra- and interspecific distances, were used to partition the 16S rRNA dataset into species hypotheses (initial partition). Resulting inferences were then recursively applied to yield finer partitions (recursive partitions) until no further partitioning was possible. ABGD analysis was run on the $16 \mathrm{~S}$ rRNA dataset through a web-based interface 
275 (http://www.abi.snv.jussieu.fr/public/abgd/) using default parameters (10 steps of intraspecific 276 divergence prior from $\mathrm{Pmin}=0.001$ to $\mathrm{Pmax}=0.10, \mathrm{X}=2$ ).

277

278

279

280

281

282

283

284

285

286

287

288

289

290

291

292

293

294

295

296

297

298

299

300

301

302

303

304

305

The GMYC method is also a single-gene approach to identifying species 'boundaries' associated with shifts in branching rates between intra- and interspecies branching events on a time-calibrated ultrametric tree (Pons et al., 2006; Fujisawa \& Barraclough, 2013). We used a Bayesian implementation of this method (bGMYC; Reid \& Carstens, 2012), which was applied to the $16 \mathrm{~S}$ rRNA data. We obtained the distribution of ultrametric phylogenetic trees of $16 \mathrm{~S}$ rRNA haplotypes with BEAST v1.8.4 (Drummond et al., 2012), then used 100 random phylogenetic trees as an input for subsequent bGMYC analysis. We ran bGMYC for 50,000 generations with burn-in 40,000 and a thinning parameter of 100 . We summarized results of bGMYC analyses in a matrix of pairwise co-assignment probabilities for each haplotype, shown as a heatmap (not presented).

In addition, both inter- and intraspecific uncorrected genetic $p$-distances were calculated using MEGA 6.1 (Tamura et al., 2013).

\section{Divergence times estimation}

Molecular divergence dating was performed in BEAST v1.8.4, including the concatenated mtDNA + nuDNA dataset. We used hierarchical likelihood ratio tests in PAML v4.7 (Yang, 2007) to test molecular clock assumptions separately for mtDNA and nuDNA markers. Based on PAML results, we then decided to use a strict clock for the nuDNA (BDNF) and an uncorrelated lognormal relaxed clock for mtDNA. We also used these models and partitioning schemes from the ML analysis. The Yule model was set as the tree prior and we assumed a constant population size and default priors for all other parameters. We conducted two runs of 100 million generations each in BEAST v1.8.4. We also assumed parameter convergence in Tracer and discarded the first $10 \%$ of generations as burn-in. We used TreeAnnotator v1.8.0 (in BEAST) to create our maximum credibility clades.

Since we could find no paleontological data for the Microhylinae, we relied on three recently estimated calibration priors for this subfamily obtained from recent large-scale phylogenies of microhylids (Kurabayashi et al., 2011), and a fossil record of Gastrophryninae (Sanchiz, 1998; Holman, 2003; de Sá et al., 2012) as primary calibration points. We also applied two additional calibration points widely used in divergence time estimates of Anura: maximum age of the split between Blommersia wittei and B. transmarina from the Comoro islands at 15 
306 MYA (Vences et al., 2003), and the minimum age of Alytes muletensis - A. dickhilleni split at 5

307 MYA (Fromhage et al., 2004). Calibration points and priors are summarized in Table S4.

308

309

310

311

312

313

314

315

316

317

318

319

320

321

322

323

324

325

326

327

328

329

330

331

332

333

334

335

336

\section{Ancestral area reconstruction}

To infer a biogeographic history of Microhyla, a model-testing approach was applied using the ML tree with Lagrange (Ree et al., 2005; Ree \& Smith, 2008) in RASP v3.2 (Yu et al., 2015). Species occurrences were categorized according to nine biogeographic areas, modified from Turner et al. (2001), Wood et al. (2012) and Chen et al. (2018), reflecting patterns of endemism in Microhyla (see Fig. 2A): (A) Mainland East Asia; (B) Eastern Indochina; (C) Western Indochina; (D) Indian Subcontinent; (E) Malayan Peninsula; (F) Sumatra + Java + Bali; (G) Borneo and adjacent Philippine islands; (H) Sri Lanka; and (I) East Asian islands (Taiwan + the Ryukyus) (see Supplemental Information 1 for biogeographic area definitions and references). Maximum range-size was set to three areas, as no extant species occurs in more than three biogeographical regions. Matrices of modern distributions of taxa/ area are given in Table S5. We modeled discrete state transitions (for ranges) on branches as functions of time, enabling ML estimation of where ancestral linneages' geographic areas were at the time of cladogensis. A Lagrange analysis found ancestral area(s) at a node, split areas into two distinct lineages, and calculated probabilities of most likely geographic areas for the nodes (Ree \& Smith, 2008). Analyses used two models (Matzke, 2013): Langrange Dispersal-Extinction-Cladogenesis (DEC; Ree \& Smith, 2008), and the ML version of Statistical Dispersal-Vicariance Analysis (S-DIVA; Ronquist, 1997). We assessed model fit using the Akaike Information Criterion (AIC) and Akaike weights.

Given the tremendous geological complexity of the region through time, we applied the following time and dispersal constraints to the analyses: we set four periods, corresponding to the main stages of gradual ISC movements northwards, formation of the first land bridges between the ISC and Southeast Asia, and final accretion between the ISC and the Asian mainland based on data from recent geologic models (based on Hall, 2012; Ding et al., 2017; Morley, 2018; see Fig. 3 for schematic paleogeographic maps of South and Southeast Asia from early Paleocene to the Oligocene). The following time periods were designated: (1) 100-57 MYA corresponds to complete isolation of the ISC from Eurasia, (2) 57-50 MYA marks the first assumed land connections between India and modern-day Sumatra; (3) during 50-35 MYA the ISC likely continued counter-clockwise movement northwards, forming land bridges with 
337 modern-day Indo-Burma; and (4) 35-0 MYA corresponds to the firm collision and formation of

338 a stable land connection between the ISC and Eurasia. Transition matrices between

339 biogeographic regions for each time period are presented in Table S6.

$340 \quad$ Body size evolution

341 To assess body size evolution and miniaturization in Microhyla, we used weighted 342 squared-change parsimony (Maddison, 1991) executed with Mesquite v3.31 (Maddison \& 343 Maddison, 2017). We compiled data on maximum snout-vent length (SVL) for both sexes for 344 each Microhyla species reported in literature and/or determined from available voucher 345 specimens (see Table S7); mensural data were taken with Mitutoyo dial caliper to the nearest 0.1 mm. SVL data for all Microhyla species are collated in Table S7.

\section{Results}

\section{Taxa, data, and sequence characteristics}

Our aligned matrix of all mtDNA data comprised 2478 bp, included 206 samples, representing 48 species of Microhyla ( $96 \%$ of the currently recognized species), five species (of nine currently recognized species) of the phylogenetically closely related genus Glyphoglossus, and 24 samples from outgroup taxa (see Table S1).

The concatenated mtDNA + nuDNA dataset comprised $3207 \mathrm{bp}$, including 118 samples from 100 ingroup and 18 outgroup taxa. Summary information on fragment lengths and variability are collated in Table S8.

\section{Phylogenetic relationships and species groups in Microhyla}

Bayesian Inference and Maximum Likelihood analyses of the mtDNA-based genealogy for Microhyla and Glyphoglossus (Figs. 4 and 5; a simplified collapsed tree is shown in Fig. S2) resulted in a topology that was generally congruent with the phylogeny obtained from the concatenated mtDNA + nuDNA data, though the latter had higher support for most nodes (Fig. 6). The $B D N F$ gene haplotype network resulted in the species clusters which were generally congruent with the phylogenetically and morphologically recognized groups of Microhyla and were separated from each other by at least four mutational steps (Fig. S3). Most of the examined Microhyla species showed sharing of BDNF haplotypes with exception of the species pairs $M$. marmorata + . pulverata, M. kodial + M. irrawaddy, and M. okinavensis + Microhyla sp. 3 (Fig. S3). Overall, since the mtDNA + nuDNA phylogenetic tree was mostly better resolved and 
368 had greater support at more nodes than the mtDNA tree, we relied on the combined mtDNA + 369 nuDNA topology for inferring phylogenetic relationships and biogeographic history of the genus

370

371

372

373

374

375

376

377

378

379

380

381

382

383

384

385

386

387

388

389

390

391

392

393

394

395

396

397

398

\section{Microhyla.}

The BI- and ML-analyses of mtDNA data resulted in a majority of ingroup nodes receiving high values of both PP and BS support (Figs. 4 and 5). Observed topological patterns within the Microhyla - Glyphoglossus assemblage were generally congruent across analyses and agreed well with earlier phylogenies for the group (see Discussion), although with generally higher node support values in our study. All analyses unambiguously supported the monophyly of the Microhyla - Glyphoglossus assemblage; however, the basal node of this radiation was not sufficiently resolved in all analyses (Fig. 6 and Fig. S2). The genus Microhyla sensu lato was subdivided into two major deeply divergent groups, that we identify here as Microhyla I and Microhyla II, while monophyly of the genus with respect to Glyphoglossus was not supported according to mtDNA data (see Fig. S2); a similar pattern was also reported in the mtDNA-based genealogy of Matsui et al. (2011). Though basal divergence in the Microhyla - Glyphoglossus clade based on mtDNA + nuDNA data was also not strongly supported (Fig. 6), the topology suggesting monophyly of Microhyla I + Microhyla II agreed well with results of recent multilocus phylogenies for this group (Peloso et al., 2016; Tu et al., 2018).

All species of Microhyla I, Microhyla II, and Glyphoglossus clades were regularly grouped into one of nine well supported matrilines (Figs. 4 and 5, A-I); these same phylogenetic groupings were also revealed in the "total evidence" analysis (Fig. 6) in the BDNF haplotype network (Fig. S3) and in the most recent published phylogeny of the genus (Biju et al., 2019).

Microhyla I (subclade AI of Matsui et al., 2011) included seven major clades and 43 putative species of tiny to mid-sized terrestrial frogs (Figs. 4 and 5, A-G):

(A) Clade A corresponded to M. achatina species group and received only moderate levels of monophyly support in mtDNA-genealogy $(0.90 / 61$, hereafter node support values are given for BI PP / ML BS, respectively) (Fig. 4). Genealogical relationships within this group were poorly resolved. Phylogenetic positions of $M$. fodiens from central Myanmar, the $M$. heymonsi complex, and $M$. pineticola from Indochina were unresolved. Other species form a strongly supported monophyly (1.0/98), which is further subdivided into two subclades: (A1) comprising species from Sundaland (M. borneensis, $M$. nepenthicola, Microhyla sp. 1 from Sabah, M. malang, M. orientalis, M. mantheyi) and 
399

400

401

402

403

404

405

406

407

408

409

410

411

412

413

414

415

416

417

418

419

420

421

422

423

424

425

426

427

428

429

southern Vietnam (M. minuta) (0.97/68), and (A2) with species from Sundaland $(M$. achatina, M. gadjahmadai), Myanmar (M. irrawaddy, Microhyla sp. 4 from northern Myanmar), and southern India (M. kodial) (1.0/87). Monophyly of clade A was not supported in the "total evidence" analysis (0.72/50; Fig. 6), while the clade including all members of $M$. achatina species group except $M$. fodiens received moderate support (0.91/62; Fig. 6). The M. achatina species group occupied a more central position in the $B D N F$ gene haplotype network (Fig. S3) and was generally poorly delineated, in agreement with results of Garg et al. (2019).

(B) Clade B corresponded to M. fissipes species group (1.0/100) and consisted of two wellsupported subclades (Fig. 4): (B1) included species from Indochina and southern mainland China and Taiwan (M. fissipes, M. mukhlesuri), and species from eastern India, Bangladesh and the Andaman Islands (M. mymensinghensis, M. chakrapanii) (1.0/100); (B2) encompassing species from mainland China (M. mixtura, M. beilunensis, $M$. fanjingshanensis) and the Ryukyus (M. okinavensis, Microhyla sp. 3 from Yaeyama Archipelago) (1.0/98). In the BDNF gene haplotype network, M. okinavensis and Microhyla sp. 3 (B2) were distantly placed from members of the M. fissipes species group with a minimum of 14 mutational steps (Fig. S3), also agreeing well with results of Garg et al. (2019). The "total evidence" analysis suggested sister group relationships between M. fanjingshanensis and M. okinavensis (0.96/55; Fig. 6).

(C) Clade $\mathrm{C}$ included the $M$. berdmorei complex and M. pulchra from Indochina and southern China, as well as M. picta from southernmost Vietnam (1.0/100). Clade C was recovered as sister clade to a clade $\mathrm{A}+\mathrm{B}$ (1.0/90 for mtDNA, and 1.0/96 for "total evidence" datasets, respectively; see Figs. 5, 6); a similar topology of phylogenetic relationships was also reported by Biju et al. (2019). In our BDNF gene haplotype network, M. berdmorei species complex is separated from M. pulchra + M. picta by at least eight mutational steps (Fig. S3).

(D) Clade D encompassed species from Sri Lanka (M. zeylanica, M. karunaratnei) and southern India (M. laterite, M. sholigari, M. darreli) (D1, see Fig. 5), but also included species from northeastern India (M. eos), western Thailand (Microhyla sp. 2 from Tenasserim) and Thai-Malay Peninsula (M. superciliaris). The BDNF haplotype network suggests distant placement of Microhyla sp. 2, separated by at least seven mutational 
430

431

432

433

434

435

436

437

438

439

440

441

442

443

444

445

446

447

448

449

450

451

452

453

454

455

456

457

458

459

460

steps from other members of the M. superciliaris group (Fig. S3). The "total evidence" analysis strongly suggested sister group relationships between clades D and F (0.96/67; Fig. 6), in agreement with the phylogeny presented by Biju et al. (2019).

(E) Clade E included species with distribution on the Indian Subcontinent and Sri Lanka, including M. ornata complex (E1, M. ornata, M. nilphamariensis, M. taraiensis) and M. rubra complex members (E2, M. rubra, M. mihintalei). In the BDNF gene haplotype networks, subclades E1 and E2 are separated from each other by at least three mutational steps (Fig. S3). MtDNA data suggested a tendency for joining the Clades D and E in a monophylum (0.91/75; Fig. 5), but it was not supported by the "total evidence" analysis, which instead placed Clade $\mathrm{E}$ as a sister group to the clade $\mathrm{A}+\mathrm{B}+\mathrm{C}$, though with no support (0.70/37; Fig. 6). A similar topology was also proposed by Biju et al. (2019) but they also had insignificant node support (0.67/80). The monophyly of the clade joining matrilines A-E was moderately supported by mtDNA (Fig. 5), but not by the mtDNA+nuDNA dataset (Fig. 6).

(F) Clade F corresponds to M. butleri species group and joined the M. butleri complex from southern China and Southeast Asia with M. aurantiventris from central Vietnam (1.0/100). Clade F was strongly supported as a sister lineage with respect to Clade D based on the "total evidence" analysis (0.96/67) (Fig. 6) and the BDNF gene haplotype network (Fig. S3, separated by at least eight mutational steps). Monophyly of the clade joining D + E had moderate support in earlier phylogenies of the genus $(0.91 / 81$, see Biju et al., 2019).

(G) Clade G was represented by the M. palmipes species complex from Java and Sumatra; its phylogenetic position was poorly supported. In contrast to earlier data, suggesting sister relationships between M. palmipes and the group joining A+B+C+E clades $(0.99 / 56 ;$ Biju et al., 2019), our "total evidence" analysis suggests sister group relationships of $M$. palmipes with respect to clade $\mathrm{D}+\mathrm{F}$ but with moderate support $(0.92 / 41$; Fig. 6). The $B D N F$ gene haplotype network also places M. palmipes closer to Clade D, separated by at least seven mutational steps (Fig. S3).

Microhyla II (subclade AIII of Matsui et al., 2011) was represented by a single clade (H) and included nine nominal species of tiny to small-sized terrestrial or semi-arboreal frogs (Fig. 5, $\mathrm{H})$ : 
461 (H) Clade H corresponds to M. annectens species group and was further subdivided in two

462

463

464

465

466

467

468

469

470

471

472

473

474

475

476

477

478

479

480

481

482

483

484

485

486

487

488

489

490 subclades: (H1) included species from Borneo (M. perparva, M. petrigena), the ThaiMalay Peninsula (M. annectens), and Annamite Mountains of Indochina (M. annamensis, M. marmorata and M. pulverata) (1.0/88); and (H2) joined species from central (M. nanapollexa) and southern parts of Annamite Mountains (M. arboricola, M. pulchella). M. marmorata was recovered paraphyletic, with respect to M. pulverata (1.0/100; Fig. 5). In the $B D N F$ gene haplotype network, Clade $\mathrm{H}$ is separated from Microhyla $\mathrm{I}$ by at least 11 mutation steps; while $\mathrm{H} 1$ and $\mathrm{H} 2$ subclades are poorly delineated (Fig. S3).

Finally, the large-sized fossorial frogs of the genus Glyphoglossus (subclade AII of Matsui et al., 2011) was represented in our analysis by five of the nine recognized species; $G$. capsus from Borneo was recovered as a sister group to the clade that joined all other species from Indochina and Malay Peninsula (Fig. 5) (0.98/74). The most recent phylogenies of Microhyla did not include any species of Glyphoglossus (Garg et al., 2019; Biju et al., 2019). In our work, the genus Glyphoglossus is separated from Microhyla by at least eight mutational steps in the $B D N F$ gene haplotype network (Fig. S3).

\section{Species delimitation analyses}

The BI matrilineal genealogy for the 48 nominal Microhyla species provided an initial assessment of species-level relationships (Figs. 4 and 5). Uncorrected genetic $p$-distances in $16 \mathrm{~S}$ rRNA mtDNA gene within and among Microhyla species are given in Table S9. In addition to currently recognized taxa, our genealogy also depicted at least four lineages of Microhyla that likely represent unrecognized species (Microhyla spp. 1-4), and a number of deep lineages within species complexes (intraspecific genetic differences $p>1.5 \%$, e.g., M. malang, $M$. achatina, M. gadjahmadai, M. heymonsi, M. okinavensis, M. berdmorei, M. butleri, M. palmipes, M. petrigena, M. perparva and M. arboricola; see Table S9), potentially constituting cryptic species diversity. Generally, interspecific divergences were $p>3.0 \%$, but in some cases, intraspecific divergences exceeded interspecific divergences (Table S9).

To assess the number of putative species-level lineages within the genus Microhyla, we implemented two alternative approaches to species delimitation via tree-based bGMYC and distance-based ABGD analyses. These methods show varying performance depending on sample and population sizes, speciation rates, and other parameters, with bGMYC showing a tendency to 
491 oversplit, while ABGD often overlumps putative species; however, when these methods agree, 492 the resulting delimitation gains plausibility (Dellicour \& Flot, 2018). The combined results of 493 both bGMYC and ABGD analyses (Figs. 4 and 5; summarized in Table S10) resolved all 494 described species of Microhyla, except for M. pulverata, which was indistinguishable from $M$.

495

496

497

498

499

500

501

502

503

504

505

506

507

508

509

510

511

512

513

514

515

516

517

518

519

520 marmorata. This result is also corroborated by the mtDNA-genealogy (Fig. 5), the BDNF gene haplotype network (Fig. S3), and divergence data for 16S rRNA gene (Table S9). Both analyses suggest that species diversity within Microhyla is greatly underestimated: for 48 recognized Microhyla species included in our genealogy, the bGMYC analysis recovered 81, and ABGD recovered 63 species-level lineages (Table S10) (note that the two species missing from our analysis, M. fusca and M. darevskii, are not included in these totals). In most cases, analyses had congruent results, however in 14 species, bGMYC proposed more groups than were recovered by ABGD. Nonetheless, species delimitation analyses strongly indicate the presence of many unrecognized species-level lineages by further partitioning $M$. heymonsi (into 7 to 8 species), $M$. bermodrei (3 to 4 species), M. malang (3 species), M. butleri (2 to 4 species), and $M$. gadjahmadai, M. okinavensis, M. palmipes, M. perparva, M. petrigena, M. achatina and $M$. arboricola (each with 2 species) (Figs. 4 and 5; Table S10). For nine other taxa, the analyses gave incongruent results, with bGMYC splitting and ABGD lumping these disparate taxa $(M$. beilunensis, M. chakrapanii, M. mantheyi, M. mixtura, M. mukhlesuri, M. orientalis, M. superciliaris, Microhyla sp. 3 and Microhyla sp. 4) (Table S10).

\section{Divergence times estimation}

The resulting BEAST chronogram (see Fig. S4; BEAST results for the ingroup are further detailed in Fig. 2) elucidates that the most recent common ancestor (MRCA) of Microhyla and Glyphoglossus originated between late Paleocene and early Eocene, ca. 50.8 Ma (44.1-57.0), and agrees with the analysis of Feng et al. (2017), ca. 48.8 Ma (45.9-53.2), and is notably earlier than the estimate by Garg \& Biju (2019) as 61.5 Ma (56.6-66.5). The group Microhyla + Glyphoglossus radiated within a relatively narrow time period in the middle Eocene ca. 43.8 Ma (38.7-49.1), slightly younger than estimates of Garg \& Biju (2019), who estimated this cladogenetic event at ca. $48.7 \mathrm{Ma}$ (44.1-53.2). Diversification within the genus-level endemic radiations of Microhyla I, Microhyla II, and Glyphoglossus clades started in early to mid-Oligocene (from 35 to $25 \mathrm{Ma}$ ), generally agreeing with Garg \& Biju (2019). Estimated 
521 node-ages and the 95\% highest posterior density (95\% HPD) for the main nodes are summarized

522 in detail in Table S11.

$523 \quad$ Historical biogeography

524 We were able to reconstruct biogeographic processes (vicariance, dispersal, and 525 colonization routes) and ancestral areas (Fig. 2) for the genus Microhyla using the RASP 526 biogeographic analysis. According to both the DEC and the S-DIVA model, the MRCA of 527 Microhyla + Glyphoglossus (node 12, Fig. 2) most likely inhabited Eastern Indochina. Eastern 528 Indochina was also reconstructed as an ancestral range for Microhyla II and Glyphoglossus 529 lineages (nodes 18 and 12, respectively, Fig. 2), and Microhyla I likely originated in western 530 Indochina (node 30, Fig. 2). Microhyla II expanded its range to Borneo and the Malay Peninsula, 531 but Microhyla I dispersed more widely to all biogeographic regions within the modern range of 532 the genus, including at least five independent dispersal events from western Indochina to the 533 Indian Subcontinent (Fig. 2). Results of our analyses suggest numerous cases of dispersal from 534 the Asian mainland to islands including Sundaland, but only a single case of reverse dispersal 535 (from Borneo to the Malay Peninsula, see Fig. 2).

$536 \quad$ Body size evolution modeling

537 Reconstructions of maximum SVL ancestral states and their evolution in Microhyla and 538 Glyphoglossus are shown in Fig. 7. Maximum adult SVL differed substantially for males and 539 females, so data were analyzed separately for each sex. Glyphoglossus (adult male SVL 30.0$54095.0 \mathrm{~mm}$ ) are generally larger compared to Microhyla (adult male SVL 10.6-35.0 mm); the 541 MRCA of the Microhyla + Glyphoglossus assemblage is reconstructed as a mid-sized frog (25.0$54230.0 \mathrm{~mm}$ SVL for males, 30.0-35.0 mm for females). Most species of Microhyla were found to 543 be smaller (male SVL roughly $11.5-25.0 \mathrm{~mm}$ ) than their common ancestor, with five cases of 544 miniaturization (male SVL 11.5-15.0 mm). However, both Glyphoglossus and M. berdmorei 545 species groups of Microhyla I have subsequently increased their body size (up to $105 \mathrm{~mm}$ in 546 Glyphoglossus molossus, up to $35 \mathrm{~mm}$ in M. berdmorei) (Fig. 7).

548 Discussion

$549 \quad$ Updated phylogenetic relationships of Microhyla

550 In phylogenetic systematics, extensive taxon sampling increases accuracy and support of 551 evolutionary relationships (Zwickl \& Hillis, 2002). Herein, we present an updated phylogenetic 
552 study of the genus Microhyla, with the most complete taxon sampling including 48 of the 50

553 currently recognized species. The absent taxa in our study are $M$. fusca and $M$. darevskii - two

554 enigmatic species from central and southern Vietnam. Microhyla fusca was described from a

555 single specimen collected from southern Vietnam (Andersson, 1942); no additional specimens of

556 this species were reported after its discovery despite numerous field survey efforts. Microhyla

557 darevskii was described from a series of formalin-fixed specimens and morphologically

558 resembles members of M. berdmorei species complex (Poyarkov et al., 2014); our repeated

559 attempts to get DNA data from the type series of $M$. darevskii were not successful. Further

560 studies of museum specimens and increased field survey efforts are required to clarify the

561 taxonomic status and phylogenetic affinities of $M$. fusca and M. darevskii. We also did not

562 sample Microhyla maculifera, a small-sized species described from Danum Valley in Sabah,

563 Borneo (Inger, 1989); it might correspond to Microhyla sp. 1 in our analysis, collected from its

564 type locality. Unfortunately, specimens of Microhyla sp. 1 included in our phylogenetic analyses

565 were not available for morphological examination; we thus hesitate to identify this population as

566 M. maculifera pending further morphological study.

567 The first phylogenetic study of Asian microhylids by Matsui et al. (2011) demonstrated

568 paraphyly of Microhyla with respect to Glyphoglossus (at that time including Calluella).

569 Subsequent multilocus phylogenetic studies (Peloso et al., 2016; Tu et al., 2018; Garg \& Biju,

570 2019) strongly suggested sister group relationships between Glyphoglossus and Microhyla sensu

571 lato, but still recognized the presence of two deeply divergent lineages within Microhyla. Our

572 time-tree suggests that divergence between the two major clades of Microhyla I and Microhyla II

573 happened soon after the basal split within the Microhyla + Glyphoglossus assemblage during the

574 middle Eocene and similar divergence time estimates were obtained by a recent analysis by Garg

$575 \&$ Biju (2019). Robust phylogenies coupled with examination of external morphological and

576 osteological characters are required to assess the evolutionary differences among the three

577 subclades of the Microhyla + Glyphoglossus assemblage, likely warranting recognition as three

578 distinct genera.

579 The first classifications of the genus Microhyla into species groups were based 580 exclusively on morphological characters (Parker, 1934; Dubois, 1987; Fei et al., 2005) but have 581 not been supported by more recent molecular data (Matsui et al., 2011; Garg et al., 2019). 582 Matsui et al. (2011) assessed genealogical relationships among 20 Microhyla species and 
583 proposed recognition of five distinct species groups within the genus. Recently Garg et al. 584 (2019) proposed a new scheme for grouping Microhyla species and recognized six species 585 groups based on more extensive sampling of 33 species. Our phylogenetic hypothesis mostly 586 agrees with these earlier proposed phylogenies of the genus (Matsui et al., 2005, 2011, 2013; 587 Matsui, 2011; Hasan et al., 2012, 2014a; Howlader et al., 2015; Peloso et al., 2016; 588 Wijayathilaka et al., 2016; Seshadri et al., 2016; Yuan et al., 2016; Khatiwada et al., 2017; Tu et 589 al., 2018; Garg et al., 2019; Nguyen et al., 2019; Poyarkov et al., 2019; Biju et al., 2019), and a 590 much more extensive taxon sampling allows us to revise species groups more accurately in 591 Microhyla (Fig. 6).

592 The Microhyla achatina group (Clade A, Figs. 4 and 6; part of group AId2 of Matsui et 593 al., 2011) includes species mostly from Southeast Asia (M. achatina, M. gadjahmadai, M. 594 heymonsi, M. pineticola, M. minuta, M. mantheyi, M. orientalis, M. malang, M. nepenthicola, M. 595 borneensis, Microhyla sp. 1), but also from Myanmar (M. irrawaddy, M. fodiens, Microhyla sp. 596 4) and southern India (M. kodial). This group includes tiny (male SVL $10.6 \mathrm{~mm}$, Das \& Haas, 597 2010) to mid-sized (male SVL $29.1 \mathrm{~mm}$, Poyarkov et al., 2019) frogs with lateral nostrils; dorsal 598 skin shagreened to prominently granular skin; small disks on digits usually present and typically 599 bearing terminal grooves; toe webbing rudimentary or absent; inner metatarsal tubercle rounded 600 or oval-shaped, outer metatarsal tubercle rounded and small, or large, shovel-shaped (in $M$. 601 fodiens, Poyarkov et al., 2019); usually with a mid-dorsal line or skinfold and a light streak 602 extending from posterior corner of eye to axilla (Garg et al., 2019). The phylogenetic position of 603 M. minuta, M. pineticola, and M. borneensis sensu stricto was assessed for the first time. 604 Vietnamese M. minuta was recovered as a member of subgroup A1, joining species from 605 Peninsular Malaysia (M. mantheyi), Java + Bali (M. orientalis), and Borneo (M. malang, M. 606 nepenthicola, M. borneensis, Microhyla sp. 1). Our study also supports previously reported 607 placement of south Indian M. kodial in one clade with Myanmar species M. irrawaddy and M. 608 sp. 4 (Poyarkov et al., 2019); this clade is sister to the M. achatina + M. gadjahmadai clade from 609 Java and Sumatra (subgroup A2). Unfortunately, phylogenetic positions of the M. heymonsi 610 complex and $M$. pineticola remain unresolved. The morphologically different semi-fossorial $M$. 611 fodiens from central Myanmar, previously identified as M. rubra (Wogan et al., 2008; Peloso et 612 al., 2016), or M. cf. berdmorei (Garg et al., 2019), clearly belongs to this group and forms a 613 highly divergent lineage (Poyarkov et al., 2019). 
615 2011) joins species from East Asia (M. fissipes, M. mixtura, M. beilunensis, M. okinavensis, M. 616 fanjingshanensis and Microhyla sp. 3), Indochina, and eastern India (M. mukhlesuri, M. 617 mymensinghensis, M. chakrapanii). We also agree with Garg et al. (2019) in recognizing this 618 species group as distinct from the M. achatina group, though monophyly of the latter is only 619 moderately supported (Fig. 4). Members of this group are in general morphologically similar to 620 M. achatina species group, but can be distinguished from the latter by finger tips lacking disks, 621 toe tips rounded or bearing tiny disks lacking terminal grooves; by inner metatarsal tubercle 622 elongated, outer metatarsal tubercle small, rounded; and by a dark band running from canthus 623 rostralis posteriorly towards groin and posterior parts of belly (Garg et al., 2019). Our phylogeny 624 recovered two well-supported subgroups within the $M$. fissipes group corresponding to 625 Indochinese (B1) and East Asian (B2) taxa (Fig. 6) (Yuan et al., 2016), supported sister 626 relationships of M. chakrapanii and M. mymensinghensis (Garg et al., 2019), and suggested sister group relationships of M. fanjingshanensis and M. okinavensis (Fig. 6).

The Microhyla berdmorei group (Clade C, Figs. 5 and 6; group AId1 of Matsui et al., 2011) encompasses the largest Microhyla species and, according to our data, includes the wideranging $M$. berdmorei complex (SVL up to $45.6 \mathrm{~mm}$; Southeast Asia), M. pulchra (SVL up to $36.5 \mathrm{~mm}$; Indochina and southern China), and stout-bodied semi-fossorial $M$. picta from southern Vietnam (SVL up to $33.4 \mathrm{~mm}$ ). The phylogenetic position of M. picta was investigated here for the first time, and was recovered as sister taxon to M. pulchra. Members of the $M$. berdmorei species group exhibit considerable morphological differentiation: smooth to sparsely granular skin on dorsum; finger tips rounded, toe tips rounded or bearing tiny disks with or without terminal grooves; toe webbing from rudimentary to complete reaching toe disks; inner metatarsal tubercle oval, outer metatarsal tubercle from small to large, shovel-shaped (in $M$. picta); lacking mid-dorsal line or skinfold; with a light streak extending from posterior corner of eye to axilla; and a characteristic bright-yellow coloration of the groin and posterior parts of the belly. Based only on morphological characteristics, the unsampled M. darevskii (absent in our phylogeny), likely belongs to this species group. 
645 sholigari, M. karunaratnei and M. darreli; M. zeylanica group of Garg et al., 2019), three 646 species from northeastern India (M. eos), western Thailand (Microhyla sp. 2) and the Malay 647 Peninsula (M. superciliaris). Morphologically members of this group are small-sized (male SVL 648 under $21.5 \mathrm{~mm}$ ), have dorsal orientation of nostrils; smooth to granular skin on dorsum; finger 649 disks rounded or with weak disks lacking terminal grooves; toe disks having terminal grooves; 650 inner metatarsal tubercle oval-shaped, outer metatarsal tubercle small and rounded; toe webbing 651 reduced or well-developed; mid-dorsal skinfold generally present; with a light streak from 652 posterior eye corner to axilla; and often with contrasting black and white blotches on belly. Garg 653 et al. (2019) proposed recognizing M. zeylanica species group for taxa inhabiting peninsular 654 India + Sri Lanka, but Biju et al. (2019) reported M. eos from northeastern India as a sister 655 lineage of this clade, refraining from assigning this species to any species group. Herein, we 656 propose recognizing the M. superciliaris species group for taxa inhabiting Southeast Asia, 657 northeastern and southern India, and Sri Lanka.

The Microhyla ornata group (Clade E; group AIb of Matsui et al., 2011) is comprised of 659 species exclusively occurring in the Indian Subcontinent, subdivided into two groups, E1 ( $M$. 660 ornata, M. nilphamariensis, and M. taraiensis; corresponds to M. ornata group of Garg et al., 661 2019), and E2 (M. rubra, M. mihintalei; corresponds to M. rubra group of Garg et al., 2019) (Figs. 5 and 6). Morphologically M. ornata group includes small to mid-sized species with 663 lateral nostrils; shagreened to granular dorsal skin; tips of digits lacking disks and terminal grooves; toe webbing rudimentary; inner and outer metatarsal tubercles present, latter may be 665 enlarged; middorsal line or skinfold present; body flanks with dark band from nostrils to groin; and a light streak from posterior eye corner to axilla. Though Garg et al. (2019) proposed recognizing the more robust, semi-fossorial species $M$. rubra and $M$. mihintalei as a distinct $M$. rubra species group, we do not follow their scheme since phylogenetic relationships within Clade E are well resolved and subclades E1 and E2 are closely related (Matsui et al., 2011). In addition, adaptations to burrowing lifestyle are not unique for M. rubra but are found in other lineages of Microhyla as well, such as M. fodiens of Clade A, and M. picta of Clade C. 5 and 6) includes the M. butleri complex from Southeast Asia and southern China and the closely 674 related $M$. aurantiventris from central Vietnam. Morphologically members of this group show a dorsolateral nostril position; prominently granular dorsal skin; presence of weak disks on digits 
676 bearing terminal grooves; moderately developed webbing on toes; inner and outer metatarsal 677 tubercles small; middorsal line or skinfold present; characteristic “teddy-bear"-shaped dark 678 marking on dorsum edged with light color; body flanks lacking dark band from nostrils to groin; 679 and a light eye-axilla streak present (Nguyen et al., 2019).

680 The Microhyla palmipes group (Clade G; group AIa of Matsui et al., 2011) presently 681 includes a single species, M. palmipes, from Java, Sumatra, and adjacent offshore islands in 682 Indonesia, and according to our data, likely represents a species complex (see below). 683 Morphological data on M. palmipes are scarce; they are small-sized frogs (male SVL 16.0 mm) 684 with lateral nostrils; shagreened skin on dorsum; weak disks on digits lacking terminal grooves; 685 moderately developed webbing on toes; inner and outer metatarsal tubercles small; middorsal 686 line absent; dark markings on flanks and a light eye-axilla streak present (Bain \& Nguyen, 2004; 687 Poyarkov et al., 2014).

688 Finally, the M. annectens group (Clade H of Microhyla II; group AIII of Matsui et al., 689 2011; Figs. 5 and 6) encompasses tiny (male SVL $13.2 \mathrm{~mm}$ ) to mid-sized (male SVL to 21.6 $690 \mathrm{~mm}$ ) frogs from Southeast Asia, and according to our phylogeny, is subdivided into two 691 subgroups: H1 comprising species from Malayan Peninsula (M. annectens), Annamite 692 Mountains in Vietnam (M. annamensis, M. marmorata, and M. pulverata), and Borneo ( $M$. 693 petrigena and $M$. perparva); and $\mathrm{H} 2$ including species from mountains of central and southern 694 Vietnam (M. arboricola, M. pulchella, M. nanapollexa). M. marmorata was found to be 695 paraphyletic with respect to $M$. pulverata. Morphologically, M. annectens group members are 696 characterized by a relatively short body; lateral position of nostrils; sparsely granular to 697 tubercular dorsal skin; complete toe webbing with well-developed, flattened, and slightly 698 expanded disks on digits bearing terminal grooves; inner metatarsal tubercle present, and outer 699 metatarsal tubercle present or absent. Further morphological studies are required to examine 700 morphological differentiation among M. annectens group members. Phylogenetic positions of $M$. 701 annamensis, M. marmorata, M. pulverata, M. arboricola, and M. pulchella are for the first time 702 reported in the present study.

703 Our updated phylogeny reveals several lineages of Microhyla that likely represent 704 undescribed species: Microhyla sp. 1 from Sabah, Malaysia (corresponds to Microhyla sp. 1 of 705 Matsui et al., 2011), Microhyla sp. 2 from western Thailand (previously not reported), Microhyla 706 sp. 3 from Yaeyama Archipelago (previously referred to as M. okinavensis), and Microhyla sp. 4 
707 from northern Myanmar (reported as Microhyla sp. A by Mulcahy et al., 2018). Our study also

708 recovered significant diversity within wide-ranging species complexes that might comprise 709 undescribed cryptic species $(\mathrm{N}=31)$. This suggests that the taxonomy of the genus Microhyla 710 still remains largely incomplete.

\section{Indian Collision and historical biogeography of Microhyla}

The origin of Asian microhylids, including the subfamily Microhylinae, is connected with a break-up of Gondwana and the Indian Collision (Van Bocxlaer et al., 2006; Van der Meijden et al., 2007). Most likely, ancestors of Asian Microhylidae subfamilies diverged and diversified on the Indian Plate during its long isolation and northward drifting in the late Cretaceous and Paleocene (Bossuyt \& Milinkovitch, 2001; Kurabayashi et al., 2011; de Sá et al., 2012) (see Fig. 3A). The basal divergence of the subfamily Microhylinae most likely took place on the Indian Plate prior to its first contact with Eurasia and the ISC is regarded as the original source of Microhylinae diversity (Garg \& Biju, 2019). However, Southeast Asia (not the ISC) presently harbors the largest number of Microhylinae lineages and species (Frost, 2020). mainland was a more complicated process than previously conceived, implicating early opportunities for faunal exchange between the ISC and present-day Southeast Asia (Klaus et al., 2010; Li et al., 2013; Grismer et al., 2016). The "Out of India" scenario, with early dispersal from the ISC to Sundaland via brief land connection in early Eocene, has also been proposed for the Microhylinae (Garg \& Biju, 2019). Recent progress in tectonic plate modeling further corroborates the possibility for biotic exchange between the ISC and Sundaland via the Incertus Arc land bridge, starting 55-50 Ma (Fig. 3B), although exact timing and configuration of the landmasses remains under debate (Hall, 2012; Ding et al., 2017). Interestingly, paleoclimate reconstructions suggest that modern-day megathermal angiosperm-dominated tropical forests also originated in the ISC. They later dispersed from there and became established across Sundaland starting about $50 \mathrm{Ma}$ (Morley, 2018) coinciding with the onset of a perhumid climate in Southeast Asia (Fig. 3B).

The present time tree analysis indicates that the ancestral radiation of Microhyla + Glyphoglossus into three main lineages (Microhyla I, Microhyla II and Glyphoglossus) happened during a short time frame in the middle Eocene (ca. $43.8 \mathrm{Ma}$ ), slightly later than previous estimates (48.7 Ma; Garg \& Biju, 2019). Our biogeographic analysis strongly suggests that the 
738 Microhyla + Glyphoglossus MRCA, as well as the Microhyla I + Microhyla II ancestor, 739 inhabited Eastern Indochina (Fig. 2), which was connected to Sundaland (Fig. 3C). Thus, our 740 results support the Southeast Asian origin of the Microhyla - Glyphoglossus assemblage in 741 contrast to the hypothesis by Garg \& Biju (2019), that suggested the dispersal of Microhyla from 742 the ISC into Asia from the Oligocene to the Miocene.

743 The Microhyla II clade remained largely within its ancestral area with most members of 744 the group inhabiting Eastern Indochina and a few species dispersing to Borneo and the Malay 745 Peninsula (Fig. 2). Compared to other Microhyla species groups, members of the Microhyla II 746 clade are generally small and associated with perhumid montane evergreen forests or tropical

747 748 749 750 751 752 753 754 755 756 757 759 760 761 762 763 764 765 766 767

758 Drifting of the ISC northwards led to a collision of the Indian plate with Eurasia from the rainforests; they do not occur in lowland seasonally dry areas. In fact, in Indochina, their distribution is restricted to mountainous areas (Parker, 1934; Poyarkov et al., 2014).

On the contrary, members of the Microhyla I clade dispersed widely and achieved a panOriental distribution (see Figs. 1 and 2). Members of this clade are diverse ecologically and morphologically. They vary in body size from the smallest to the largest Microhyla taxa, occupy habitats that include open seasonally dry savannahs (Parker, 1934), and several species within the Microhyla I clade evolved adaptations towards digging and aestivation (M. rubra, M. mihintalei, M. picta, and M. fodiens; see Poyarkov et al., 2019). The MRCA of Microhyla I is hypothesized to inhabit western Indochina, the same region reconstructed as ancestral for all major internal nodes within Microhyla I, and for a number of included lineages (M. heymonsi, M. fissipes, M berdmorei, and M. superciliaris species groups), respectively (Fig. 2). Oligocene to the Miocene (Aitchison \& Ali, 2012; Hall, 2012) (Fig. 3D). At the same time, the uplift of the Himalayas, coinciding with the middle Miocene thermal maximum, initiated the subsequent Miocene strengthening of the Indian monsoon and entailed the expansion of seasonally dry conditions across the northern parts of the Indian peninsula and Indochina. This resulted in the disappearance of closed tropical forests over much of the ISC (Morley, 2018) (Fig. 3D). Starting in the Oligocene, Indochina became the source of evergreen and seasonally dry floral elements that dispersed to the ISC with ongoing climate aridification (Morley, 2000). These conditions presumably facilitated colonization of the Indian Subcontinent by Microhyla I lineages. 
Our biogeographic analysis reveals at least five independent cases of Microhyla I

769 dispersal from Western Indochina to the ISC (see Fig. 2). Two of these took place in Late

770 Oligocene-Early Miocene: the M. superciliaris species group (29.2-22.5 Ma, Fig. 2, 1) and M.

771 ornata species group (31.4-18.8 Ma, Fig. 2, 2). Both lineages underwent significant

772 diversification in the ISC and reached as far south as Sri Lanka. Three other cases of the ISC

773 colonization by Microhyla I include more recent dispersal events in Late Miocene - Pliocene by

774 M. berdmorei (6.9-4.1 Ma, Fig. 2, 3) and M. fissipes species groups (M. mymensinghensis, 7.2-

775 5.1 Ma, Fig. 2, 4) to northeastern India and Bangladesh, with the only case of dispersal to

776 southern peninsular India being the species of $M$. achatina group in the Middle Miocene ( $M$.

777 kodial, 16.2-8.9 Ma, Fig. 2, 5). The confusing phylogenetic position of M. kodial within the

778 Southeast Asian M. achatina species group originally inspired the hypothesis that this might be a

779 result of a human-mediated dispersal and introduction (Vineeth et al., 2018). However,

780 subsequent discovery of its sister species M. irrawaddy and Microhyla sp. 4 in central Myanmar

781 have made the hypothesis of natural dispersal of the M. achatina species group members from

782 Southeast Asia to the ISC more plausible. Interestingly, M. irrawaddy inhabits seasonally dry

783 savannah areas, with minimal rainfall (Poyarkov et al., 2019). Hence, progressing aridification of

784 the northern and central parts of the ISC starting in the late Miocene (Deepak \& Karanth, 2018)

785 could have created suitable habitats facilitating dispersal of M. kodial ancestors. Generally,

786 western Indochina played an important role for the Microhyla I clade (Fig. 2) as this territory

787 likely represents a "stepping stone" area connecting Southeast Asia and the ISC (Fig. 3D).

788 Diversification within Microhyla species group-level endemic radiations started in the

789 Late Oligocene-Early Miocene and initiated multiple dispersals from Asian mainland to present-

790 day islands and archipelagos (Fig. 2). These include multiple colonizations of Sundaland from

791 both Indochina and the Malay Peninsula (by M. annectens, M. palmipes, M. berdmorei and M.

792 achatina species groups; Fig. 2). This is not surprising, since these territories are believed to

793 have been a single landmass throughout most of Cenozoic (Cannon et al., 2009; Woodruff, 2010;

794 Hall, 2012). Microhyla superciliaris and M. ornata species groups experienced at least four

795 independent dispersal events from southern India to Sri Lanka, corroborating results of recent

796 studies, and suggesting a complex history of dispersals between these regions (Harikrishnan et

797 al., 2012; Pyron et al., 2013; Agarwal et al., 2017; Karunarathna et al., 2019). Our study

798 confirms placement of $M$. chakrapanii from Andaman Islands inside the Southeast and East 
799

800

801

802

803

804

805

806

807

808

809

810

811

812

813

814

815

816

817

818

819

820

821

822

823

824

825

826

827

828

829

Asian M. fissipes species group as sister species of M. mymensinghensis (see Garg et al., 2019).

This confirms the faunal similarity of the Andamans with Southeast Asia rather than with peninsular India (see Das, 1994, 1999). Finally, members of M. achatina, M. butleri, and M. fissipes species groups have dispersed several times from the Asian mainland to East Asian islands: Taiwan (M. fissipes, M. heymonsi, and M. butleri), and two times independently colonized the Ryukyus (M. okinavensis and Microhyla sp. 3). These results also corroborate data that suggested faunal exchanges between Eurasian continent and East Asian islands (e.g. Ota, 1998; You et al., 2015; Yuan et al., 2016; Wang et al., 2017; Nguyen et al., 2020) and require further study (Lee et al, 2016; Tominaga et al., 2019).

Interestingly, our phylogeny suggests numerous dispersal events from the Asian mainland to islands, with almost no dispersals back to the mainland (except for the M. annectens ancestor that is hypothesized to have dispersed from Borneo to Malay Peninsula, see Fig. 2). This also supports results of de Bruyn et al. (2014) who demonstrated that colonization events from younger Asian islands are comparatively rare, rather showing increased levels of immigration events as compared to Indochina or Borneo. Further studies are required to elucidate the role of islands in producing and preserving diversity in Microhyla frogs.

\section{Implications for body size evolution in Microhyla}

Miniaturization is a widespread and interesting morphological and ecological phenomenon in amphibians (Hanken, 1985; Hanken \& Wake, 1993; Rieppel, 1996). It is common in several groups of frogs (Clarke, 1996; Lehr \& Coloma, 2008) and reaches extremes in the Microhylidae (Kraus, 2011; Rittmeyer et al., 2012; Oliver et al., 2017; Rakotoarison et al., 2017; Scherz et al., 2019). The smallest Microhylinae and the smallest terrestrial vertebrate in Asia belong to Microhyla and include representatives of two different lineages within the genus: Microhyla I (M. nepenthicola, adult male size from $10.6 \mathrm{~mm}$; see Das \& Haas, 2010) and Microhyla II (M. perparva, males $10.5-11.9 \mathrm{~mm}$, and M. arboricola, adult male size from 13.2 mm; see Inger \& Frogner, 1979; Poyarkov et al., 2014). Osteological consequences of miniaturization in Microhyla are not well studied yet diminutive species in Microhyla II clade show partial (M. arboricola) or almost complete (M. perparva, M. nanapollexa) reduction of the first finger. Similar patterns have also been reported in other miniature microhylids (e.g. Kraus, 2011; Rakotoarison et al., 2017), however, patterns and drivers of body size evolution in Microhyla remain poorly understood. 

analyses revealed generally similar patterns of body size evolution in both sexes (Fig. 7). According to the most plausible scenario, the common ancestor of the Microhyla + Glyphoglossus assemblage was a mid-sized frog (male SVL 25-30 mm, female SVL 30-35 mm).

834 Body size increased in the Glyphoglossus clade (up to $105 \mathrm{~mm} \mathrm{SVL}$ ), was slightly reduced in the 835 Microhyla I clade, and significantly reduced in the Microhyla II clade ancestors (see Fig. 7). Microhyla II members are all small-sized ( $<25 \mathrm{~mm}$ SVL in males) and three species of this group reach extreme miniaturization (<15 mm SVL in males; M. arboricola, M. perparva, $M$. nanapollexa). Microhyla I clade shows significant variation in body size: the $M$. berdmorei species group and, to a lesser extent, several species in other lineages (including M. fodiens, $M$. rubra, M. mihintalei, M. aurantiventris) demonstrate increased body sizes, while members of two lineages within M. achatina (M. nepenthicola + M. borneensis + Microhyla sp. 1) and $M$. superciliaris species groups (M. superciliaris + Microhyla sp. 2) are diminutive (Fig. 7).

Our analyses suggest that adult body size has independently changed several times in the 844 evolution of the Microhyla + Glyphoglossus assemblage. At least two lineages show an increase 845 in body size, while four other lineages demonstrate extreme miniaturization (Fig. 7). Significant increases in body size in these frogs seem to be connected with a fossorial life style. For example, 847 all members of Glyphoglossus as well as some large Microhyla (M. picta, M. fodiens, M. rubra 848 and M. mihintalei) have stout body habitus and are excellent burrowers (Poyarkov et al., 2019). Most of these species inhabit open seasonally dry habitats at low elevations and burrowing is an 850 important strategy for aestivation during dry periods. Increased body size might not only 851 facilitate digging, but is also advantageous due to lower surface-area to volume ratios, hence 852 leading to less evaporative water loss during aestivation (Tracy et al., 2010). al., 2019), but are probably connected with life history strategies, such as exploiting new food resources (Lehr \& Coloma, 2008) or adaptation to specific microhabitats such as leaf-litter or 856 moss (Kraus, 2011). Scherz et al. (2019) noted that one miniaturized Malagasy microhylid 857 species is arboreal and breeds in water-filled leaf-axil phytotelmata, while all others are 858 terrestrial. Interestingly, at least the three smallest known Microhyla species are also obligatory 859 phytotelm-breeders and reproduce in water-filled pitcher-plants (M. nepenthicola, see Das \& 860 Haas, 2010; and M. borneensis, see Parker, 1928) or water-filled tree hollows (M. arboricola, 
861 see Poyarkov et al., 2014; Vassilieva et al., 2017). Among all other Microhyla species, M.

862 arboricola is the only known arboreal species with a unique reproductive mode: developing 863 tadpoles of this species are obligately oophagous (Vassilieva et al., 2017). Microhyla arboricola 864 has a reduced clutch size (16 \pm 8 eggs), compared to other Microhyla species (usually over 400 865 eggs per clutch) (Vassilieva et al., 2017). Egg size appears to be one of the main constraints for 866 miniaturization in animals (Polilov, 2015). On one hand, reduced clutch size might favor the 867 choice of phyototelmata for reproduction due to the absence or low density of predators in such 868 habitats; on the other hand, diminutive body size might be advantageous for phytotelmic frogs 869 because it allows them to exploit smaller phytotelmata than are available to larger frogs (Scherz 870 et al., 2019). Breeding biology of M. petrigena and M. nanapollexa is not yet reported. However, 871 our field observations suggest that the latter species also reproduces in tree hollows. Further 872 studies might shed light on evolutionary interdependencies between phytotelm-breeding and 873 extreme miniaturization in Microhyla.

\section{Taxonomic implications and cryptic diversity in Microhyla}

Diminutive frogs are recognized as a source of astonishingly high undescribed cryptic diversity at different taxonomic levels due to incomplete phylogenetic information and widespread homoplasies in morphology (Hanken \& Wake, 1993; Rittmeyer et al., 2012; Scherz et al., 2019). Until recently most miniature frog groups also attracted little attention by taxonomists (e.g. Rakotoarison et al., 2017). This is also true for the genus Microhyla as the only available systematic study addressing the genus by Matsui et al. (2011) provided important insights on phylogeny and taxonomy of these frogs, but did not provide other insights. In accordance with results of Matsui et al. (2011), our phylogeny indicates that morphology-based classification schemes of Parker (1934), Dubois (1987), and Fei et al. (2005) do not reflect actual phylogenetic relationships among Microhyla species, most likely due to high frequency of homoplasies both in adult and larval morphology. Further thorough morphological and osteological studies along with a robust phylogeny are required to diagnose supraspecific-level taxa within the Microhyla + Glyphoglossus assemblage.

Since the sampling used in Matsui et al. (2011) was incomplete, and the number of recognized Microhyla species has since increased almost two-fold, many questions of Microhyla taxonomy remain unaddressed. In the present paper, we used an updated and almost complete 891 phylogeny of the genus along with species delimitation methods to resolve several long-standing 
892 areas of confusion in the genus Microhyla. Our analyses suggest that despite recent progress in

893 Microhyla taxonomy, the current number of recognized Microhyla species is still greatly 894 underestimated. Based on species delimitation analyses, 15 (ABGD estimate) to 33 lineages 895 (bGMYC estimate) probably reflect new species requiring formal description (Table S10). 896 However, due to possible overlap in levels of intra- and interspecific divergence, species 897 delineation in Microhyla based on genetic differentiation alone is problematic (Garg et al., 2019). 898 An integrative approach including morphology and acoustics must be applied for further 899 progress in Microhyla taxonomy (Rakotoarison et al., 2017).

900 Below we give a brief summary of taxonomic implications of our results. The smallest 901 member of the genus, M. nepenthicola, was described by Das \& Haas (2010) from Kubah, 902 Sarawak, but was synonymized with M. borneensis by Matsui (2011) based on morphological 903 examination of the M. borneensis holotype from Kidi (sic for Bidi), Sarawak, Borneo (Parker, 904 1928). Matsui (2011) did not include in his molecular analysis materials from the type locality of 905 M. borneensis; however, his taxonomy was widely accepted (Frost, 2020). We analyzed 906 topotypic M. borneensis specimen from the Bidi region (Fig. 4), specifically, from the Deded 907 Krian National Park, near Bau, western Sarawak, and show it be a sister species of $M$. 908 nepenthicola, and sufficiently divergent from the latter in $16 \mathrm{~S}$ rRNA sequences $(p=4.6 \%$, Table 909 S9) to constitute a separate species. The bGMYC analysis also supports distinctiveness of $M$. 910 nepenthicola from M. borneensis (Fig. 4). The name-bearing population from the former locality

911 (M. nepenthicola) is found on sandstone massifs of western Sarawak, and is diagnosable in 912 showing a pale brown dorsum with darker subtriangular pattern on scapular region, its adjacent 913 areas lacking dark variegation; and flanks with an elongated dark area. On the other hand, the 914 latter population (M. borneensis), restricted to the limestone hills of the interior, shows a grey915 brown dorsum, areas outside dark subtriangular pattern with dark grey variegation; and flanks 916 with isolated dark blotches. Therefore, we propose to revalidate the species M. nepenticola Das $917 \&$ Haas, 2010. Our data further suggest that M. borneensis, M. nepenthicola, and Microhyla sp. 1 918 from Sabah form a clade of morphologically similar and closely related taxa. Further studies are 919 required to fully clarify morphological differences between M. nepenthicola and Microhyla sp. 1. 920 Significant genetic differentiation is revealed within several species of the M. achatina 921 species group suggesting presence of cryptic diversity. Examples include M. malang (3 putative 922 species: populations from Sarawak, Sabah and Kalimantan); M. orientalis (2 putative species: 
923 populations from Bali and Java; our study confirms the occurrence of $M$. orientalis in Java); $M$.

924 mantheyi (2 putative species within Malayan Peninsula); M. achatina (2 putative species within

925 Java); and M. gadjahmadai (2 putative species within Sumatra) (see Fig. 4). Genetically, the

926 most diverse cryptic species complex in Microhyla is the M. heymonsi complex. Earlier studies

927 already recognized the presence of several deeply divergent intraspecific lineages within $M$.

928 heymonsi (Garg et al., 2019). Our new analyses revealed 7-8 highly divergent $(p>3.0 \%)$

929 lineages from China and northern Vietnam, Thailand and Laos, Thailand and south Vietnam,

930 Taiwan, Myanmar, peninsular Malaysia, and Sumatra (Fig. 4). The taxonomic status of these

931 lineages has yet to be assessed. Our study also confirms the clear distinctiveness of an

932 undescribed species Microhyla sp. 4 from northern Myanmar, and the full species status of $M$.

933 minuta, M. pineticola, M. Irrawaddy, and M. fodiens, respectively.

934 Within the M. fissipes species group, the bGMYC analysis indicated the presence of three

935 cryptic species-level lineages within M. mukhlesuri, although the ABGD analysis lumped $M$.

936 mukhlesuri with M. fissipes (Fig. 4). Significant genetic differentiation in mtDNA-markers was

937 reported for M. mukhlesuri by Yuan et al. (2016), but they were not corroborated by nuclear

938 DNA. Further integrative studies are required to assess variation within M. mukhlesuri. Deep

939 divergence was revealed between populations of M. okinavensis from Okinawa and Amami

940 islands $(p=4.8 \%$ ); populations from Yaeyama Archipelago formerly treated as M. okinavensis

941 grouped with M. mixtura and most likely represent an undescribed species, Microhyla sp. 3

942 (Tominaga et al., 2019; Hasan et al., 2014a). Shallow divergence was also found among

943 populations of M. chakrapanii from different islands of the Andaman Archipelago (Fig. 4).

944 Substantial genetic divergences also uncovered cryptic species lineages within the $M$.

945 berdmorei species complex (Fig. 5) (Hasan et al., 2012). The bGMYC analysis suggested 946 presence of four distinct groups from Malayan Peninsula, Malaysia + Sumatra + Borneo, 947 Indochina, and Bangladesh. Populations from northern Thailand previously described as $M$. 948 fowleri are grouped within the Indochinese lineage of M. berdmorei, suggesting synonymy of the 949 former (see Matsui et al., 2011). Further studies, including examination of topotype material for 950 M. berdmorei (Myanmar) and M. darevskii (central Vietnam), are needed to estimate taxonomic 951 statuses of these newly revealed lineages and extent of their distribution. Within the $M$. 952 superciliaris group, our study confirmed occurrence of $M$. superciliaris in southern Thailand 953 (Songkhla), however the deep divergence of this population from the M. superciliaris population 
954 in Malaysia ( $p=1.6 \%$ ) suggests that it is necessary to reevaluate the taxonomy of Thai 955 populations (Fig. 5). We also report an undescribed species Microhyla sp. 2, occurring in western 956 Thailand where genetic variation among examined populations (Suratthani and Phetchaburi) also 957 suggests presence of two cryptic lineages.

958 For the M. butleri species group, our work confirms deep divergence and full species 959 status of the recently described M. aurantiventris (Nguyen et al., 2019), but also reveals 960 additional undescribed lineages within M. butleri that we treat here as a species complex. From 961 two (ABGD) to four (bGMYC) cryptic lineages were recovered within this complex, with the 962 most divergent lineages being distributed in Taiwan + mainland China versus the rest of the 963 species range in Indochina and the Malay Peninsula (Fig. 5). We included only two M. palmipes 964 samples in our analysis that were notably divergent in $16 \mathrm{~S}$ rRNA sequences $(p=3.6 \%)$ and 965 originated from Bali and Sumatra; likely they both represent distinct species.

966 For the M. annectens species group, our species delimitation analyses reveal a number of 967 cryptic and undescribed lineages. Our study confirms genetic distinctiveness of recently 968 described M. arboricola and M. pulchella (Poyarkov et al., 2014), as well as of M. annamensis, 969 for which genetic information was not previously available. We also added to our analysis a 970 number of populations of $M$. marmorata throughout the species' range and for the first time, 971 including specimens of M. pulverata (collected from ca. $10 \mathrm{~km}$ north of the type locality in Gia 972 Lai Province, central Vietnam). Both species were described by Bain \& Nguyen (2004) based on 973 morphological evidence and the main characters considered to be diagnostic for these species 974 were belly coloration (marbled in M. marmorata versus dusty in M. pulverata) and skin texture.

975 Our genetic data reveal almost no genetic differentiation between samples of $M$. marmorata and 976 the topotypic $M$. pulverata ( $p=0.4 \%$, see Table S9), the latter are nested within the $M$. 977 marmorata radiation and do not form a clade (Fig. 5). Moreover, our observations showed that 978 belly coloration is highly variable within M. marmorata, especially in the southern part of the 979 species range, and cannot be used as a reliable diagnostic character. Due to the lack of genetic 980 and morphological differentiation, we hereby formally treat Microhyla pulverata Bain \& Nguyen, 9812004 as a subjective junior synonym of Microhyla marmorata Bain \& Nguyen, 2004. Some 982 other species of the M. annectens species group show deep intraspecific divergences in 16S 983 rRNA sequences, such as $M$. arboricola $(p=2.6 \%$ between populations from Dak Lak and 984 Khanh Hoa provinces of Vietnam), M. petrigena ( $p=3.7 \%$ between populations from Sarawak 
985

986

987

988

989

990

991

992

993

994

995

996

997

998

999

1000

1001

1002

1003

1004

1005

1006

1007

1008

1009

1010

1011

1012

1013

1014

1015

and Sabah), and M. perparva ( $p=5.1 \%$ between populations from Sarawak and Indonesian Kalimantan) (Fig. 5). It is likely that these lineages represent distinct species, including several new taxa awaiting formal description.

\section{Conclusions}

Herein, we provide an updated phylogenetic hypothesis for the genus Microhyla. An exhaustive taxonomic sampling for this group is challenging due to the high number of narrowranged or point-endemic species across South and Southeast Asia. In the present study, however, we examined mtDNA and nuDNA markers for 48 of 50 recognized Microhyla species (96\%), including 12 nominal species and several undescribed candidate species that have not been examined phylogenetically before our work, thus providing the most comprehensive taxonomic sampling for Microhyla to date. Our data further highlight the importance of broad phylogenetic sampling and ground-level field research to gather an accurate picture of global biodiversity, phylogenetic relationships, and evolutionary patterns in cryptic groups such as microhylid frogs.

We recognize nine species groups within the Microhyla - Glyphoglossus assemblage ( $M$. achatina, M. fissipes, M. berdmorei, M. superciliaris, M. ornata, M. butleri, M. palmipes, M. annectens species groups and Glyphoglossus), divided into three clades of probable genus-level differentiation: Microhyla I, Microhyla II and Glyphoglossus. Further integrative research combining phylogenetic and morphological lines of evidence is required to fully diagnose these recognized groups and test our taxonomic arrangement. The basal radiation of the MicrohylaGlyphoglossus assemblage is dated to the middle Eocene and likely took place in Southeast Asia. Following drifting of the Indian Plate northwards and formation of firm land bridges between the subcontinent and Asian mainland in Oligocene, ancestors of Microhyla colonized India several times from Southeast Asia and later diversified there. Our analysis also suggests that such dispersal occurred independently in five different species groups of the Microhyla II clade. Our results further corroborate the growing set of evidence for early-Eocene land connections between the Indian Subcontinent and Southeast Asia. Progressing aridification since the late Oligocene - Miocene likely facilitated dispersal of Southeast Asian biotic elements to India including the ancestral lineage-genus Microhyla. Our study further highlights the importance of Indochina not only as a cradle of autochthonous amphibian diversity and a key evolutionary hotspot for the herpetofauna (Bain \& Hurley, 2011; Geissler et al., 2015; de Bruyn et al., 2014), 
1016 but also as a stepping stone facilitating dispersal between Sundaland, the Indian Subcontinent, 1017 and East Asia (e.g. Wood et al., 2010; Chen et al., 2017; Suwannapoom et al., 2018; Poyarkov et 1018 al., 2018b). Further phylogenetic studies across different faunal groups with Indo-Southeast 1019 Asian affinities are required to clarify impact of complex paleogeography and paleoclimate 1020 history on formation of extant biodiversity in Asia.

Comprising the smallest tetrapods in Asia, frogs in the genus Microhyla represent a 1022 potential model group to study evolutionary drivers and constraints of vertebrate miniaturization. 1023 Our study suggests that four groups of Microhyla independently achieved extreme 1024 miniaturization with adult body sizes $<15 \mathrm{~mm}$. Evolution of body size in Microhyla Glyphoglossus assemblage seems to be driven by natural history: the largest body sizes are observed in burrowing species adapted to aestivation during the dry season, while three of the five smallest known Microhyla species occur only in perhumid montane forests and are phytotelm-breeders. Further research is required on how reproductive ecology in phytotelmata, often leading to reduction of clutch size, facilitates extreme miniaturization in Microhyla.

The present work clearly indicates a vast underestimation of diversity and species richness of Microhyla. We revalidate $M$. nepenthicola as a valid species, synonymize $M$. pulverata with M. marmorata, confirm species-level differentiation for a number of taxa not included in earlier phylogenies, and reveal a large number of cryptic lineages representing putative undescribed species. Alternative approaches to species delimitation suggest that at least 15 to 33 lineages of Microhyla likely correspond to species-level differentiation. Further integrative studies combining genetic, morphological, and acoustic parameters are essential for a better understanding of evolutionary relationships and taxonomy within this morphologically cryptic and diverse radiation of Asian frogs.

\section{Acknowledgements}

We are extremely thankful to all colleagues who helped during fieldwork, donated or facilitated obtaining samples, or discussed our hypotheses and results: S. Shonleben, V. F. Orlova, R. A. Nazarov, N. B. Ananjeva, N. L. Orlov, A. B. Vassilieva, E. A. Galoyan, D. Gabadage, M. Botejue, M. Madawala, Than Zaw, T. V. Nguyen, S. N. Nguyen, K.-H. Lee, Y.-P. Lin, H.-Y. Tseng, S.-F. Yang, O. S. Bezman-Moseiko, T. Neang, H. N. Nguyen, T. Igawa, S. 
1047 and P. Geissler. We thank A. M. Fetisova and E. S. Popov for providing important information 1048 and references on tectonics, paleogeography, and climate evolution in Asia. We are grateful to S. 1049 Shonleben, V. D. Kretova, T. V. Duong, S. Komaki, A. S. Dubrovskaya, P. V. Yushchenko, S. S. 1050 Idiiatullina, and A. N. Kuznetsov for tremendous help during our work on this project. We are 1051 also deeply grateful to Seshadri K. S., John Measey, M. D. Scherz, and an anonymous reviewer 1052 for useful comments and suggestions that helped us to improve the earlier version of the 1053 manuscript.

1054

1055 References

1056Acton GD. 1999. Apparent polar wander of India since the Cretaceous with implications for 1057 regional tectonics and true polar wander. In: Radhakrishna T, Piper JDA (Eds.) The Indian 1058 Subcontinent and Gondwana: a Palaeomagnetic and Rock Magnetic Perspective. Memoires of 1059 Geological Society of India, 44:129-175.

1060Agarwal I, Biswas S, Bauer AM, Greenbaum E, Jackman TR, de Silva A, Batuwita S. 2017. 1061 Cryptic species, taxonomic inflation, or a bit of both? New species phenomenon in Sri Lanka as 1062 suggested by a phylogeny of dwarf geckos (Reptilia, Squamata, Gekkonidae, Cnemaspis). 1063 Systematics and Biodiversity 15:1-13.

1064Aitchison JC, Ali JR, Davis AM. 2007. When and where did India and Asia collide? Journal of 1065 Geophysical Research: Solid Earth 112:B05423.

10664itchison JC, Ali JR. 2012. India-Asia collision timing. Proceedings of the National Academy of 1067 Sciences 109(40):E2645-E2646.

10684li JR, Aitchison JC. 2008. Gondwana to Asia: Plate tectonics, paleogeography and the biological 1069 connectivity of the Indian subcontinent from the Middle Jurassic through latest Eocene (166-35 1070 Ma). Earth-Science Reviews 88:145-166.

1074li JR, Aitchison JC. 2012. Comment on "Restoration of Cenozoic deformation in Asia and the 1072 size of Greater India” by D. J. J. Van Hinsbergen et al. Tectonics 31:TC4006.

1073AmphibiaWeb. 2020. Information on Amphibian Biology and Conservation [web application], 1074 Berkeley, California: AmphibiaWeb. Available at http://amphibiaweb.org (accessed 30 March 1075 2020). 
1076An Z, Kutzbach JE, Prell WL, Porter SC. 2001. Evolution of Asian monsoons and phased uplift 1077 of the Himalaya-Tibetan Plateau since late Miocene times. Nature 411:62-66. 1078 https://doi.org/10.1038/35075035

1079Andersson LG. 1942. A small collection of frogs from Annam collected in the years 1938-1939 by 1080 Bertil Björkegren. Arkiv för Zoologi, Stockholm 34(6):1-11.

108Bain RH, Hurley MM. 2011. A biogeographic synthesis of the amphibians and reptiles of 1082 Indochina. Bulletin of the American Museum of Natural History 2011(360):1-38.

108Bain RH, Nguyen QT. 2004. Three new species of narrow-mouth frogs (genus: Microhyla) from 1084 Indochina, with comments on Microhyla annamensis and Microhyla palmipes. Copeia 1085 2004(3):507-524.

108Bain R, Biju SD, Brown RM, Das I, Diesmos AC, Dutta S, Gower D, Inger R, Iskandar D, 1087 Kaneko Y, Lau MW. 2008. Amphibians of the Indomalayan realm. In: Stuart S.N. Threatened 1088 Amphibians of the World. Lynx Ediciones, Barcelona, Spain. 74-79.

108\$iju SD, Bossuyt F. 2003. New frog family from India reveals an ancient biogeographical link with 1090 the Seychelles. Nature 425(6959): 711-714.

109Biju SD, Garg S, Kamei RG, Maheswaran G. 2019. A new Microhyla species (Anura: 1092 Microhylidae) from riparian evergreen forest in the eastern Himalayan state of Arunachal 1093 Pradesh, India. Zootaxa 4674:100-116.

1094Bossuyt F, Milinkovitch MC. 2001. Amphibians as indicators of early Tertiary "out-of-India" 1095 dispersal of vertebrates. Science 292(5514):93-95.

1096annon CH, Morley RJ, Bush ABG. 2009. The current refugial rainforests of Sundaland are 1097 unrepresentative of their biogeographic past and highly vulnerable to disturbance. Proceedings of 1098 the National Academy of Sciences 106:11188-11193.

109 Chen J-M, Poyarkov NA, Suwannapoom C, Lathrop A, Wu Y-H, Zhou W-W, Yuan Z-Y, Jin 1100 J-Q, Chen H-M, Liu H-Q, Nguyen TQ, Nguyen SN, Duong TV, Eto K, Nishikawa K, 1101 Matsui M, Orlov NL, Stuart BL, Brown RM, Rowley JJL, Murphy RW, Wang Y-Y, Che J. 1102 2018. Large-scale phylogenetic analyses provide insights into unrecognized diversity and 1103 historical biogeography of Asian leaf-litter frogs, genus Leptolalax (Anura: Megophryidae). 1104 Molecular Phylogenetics and Evolution 124:162-171.

110Chen JM, Zhou WW, Poyarkov NA, Stuart BL, Brown RM, Lathrop A, Wang YY, Yuan ZY, 1106 Jiang K, Hou M, Chen HM. 2017. A novel multilocus phylogenetic estimation reveals 
1107 unrecognized diversity in Asian horned toads, genus Megophrys sensu lato (Anura: 1108 Megophryidae). Molecular Phylogenetics and Evolution 106:28-43.

110 Clarke BT. 1996. Small size in amphibians — its ecological and evolutionary implications. 1110 Symposia of the Zoological Society of London, 69:201-224.

111 Conti E, Eriksson T, Schönenberger J, Sytsma KJ, Baum DA. 2002. Early Tertiary out-of-India 1112 dispersal of Crypteroniaceae: Evidence from phylogeny and molecular dating. Evolution 1113 56(10):1931-1942.

1114Das I, Haas A. 2010. New species of Microhyla from Sarawak: Old World's smallest frogs crawl 1115 out of miniature pitcher plants on Borneo (Amphibia: Anura: Microhylidae). Zootaxa 2571:37111652.

111Das I. 1994. A check-list of the amphibians and reptiles of Andaman and Nicobar Islands. Journal 1118 of the Andaman Science Association 10(1):44-49.

1119as I. 1999. Biogeography of the amphibians and reptiles of the Andaman and Nicobar Islands. In:

1120 H. Ota (Ed.). Tropical island herpetofauna. Origin, current diversity and conservation. pp:431121 77. Elsevier Science B.V., Amsterdam.

112Datta-Roy A, Karanth KP. 2009. The out-of-India hypothesis: What do molecules suggest? 1123 Journal of biosciences 34(5):687-697.

1124Dayanandan S, Aston PS, Williams SM, Primack RB. 1999. Phylogeny of the tropical tree family 1125 Dipterocarpaceae based on nucleotide sequences of the chloroplast rbcL gene. American journal 1126 of Botany 86:1182-1190.

112De Bruyn M, Stelbrink B, Morley RJ, Hall R, Carvalho GR, Cannon CH, Van den Bergh G, 1128 Meijaard E, Metcalfe I, Boitani L, Maiorano L, Shoup R, von Rintelen T. 2014. Borneo and 1129 Indochina are major evolutionary hotspots for Southeast Asian biodiversity. Systematic Biology 1130 63:879-901.

1131le Sá RO, Streicher JW, Sekonyela R, Forlani MC, Loader SP, Greenbaum E, Richards S, 1132 Haddad CF. 2012. Molecular phylogeny of microhylid frogs (Anura: Microhylidae) with 1133 emphasis on relationships among New World genera. BMC Evolutionary Biology 12(1):241.

1134Deepak V, Karanth P. 2018. Aridification driven diversification of fan-throated lizards from the 1135 Indian subcontinent. Molecular Phylogenetics and Evolution 120:53-62 DOI 1136 10.1016/j.ympev.2017.11.016. 
113Dellicour S, Flot J-F. 2015. Delimiting species-poor datasets using single molecular markers: a 1138 study of barcode gaps, haplowebs and GMYC. Systematic Biology 64:900-908.

1139ellicour S, Flot J-F. 2018. The hitchiker's guide to single-locus species delimitation. Molecular 1140 Ecology Resources 18:1234-1246 DOI: 10.1111/1755-0998.12908

114Ding L, Maksatbek S, Cai F, Wang H, Song P, Ji W, Xu Q, Zhang L, Muhammad Q, Upendra 1142 B. 2017. Processes of initial collision and suturing between India and Asia. Science China Earth 1143 Sciences 60(4):635-651.

11440rummond AJ, Suchard MA, Xie D, Rambaut A. 2012. Bayesian phylogenetics with BEAUti 1145 and the BEAST 1.7. Molecular Biology and Evolution 29:1969-1973.

114Фubois A. 1987. Miscellanea taxinomica batrachologica (II). Alytes 6:1-9.

114Dutta SK, Vasudevan K, Chaitra MS, Shanker K, Aggarwal R. 2004. Jurassic frogs and the 1148 evolution of amphibian endemism in the Western Ghats. Current Science 86:211-216.

114Фyer PA, Seltzer R, Reiner-Brodetzki T, Hefetz A. 2017. An integrative approach to untangling 1150 species delimitation in the Cataglyphis bicolor desert ant complex in Israel. Molecular 1151 phylogenetics and evolution 115:128-139.

115Fei L, Ye C-Y, Jiang J, Xie F, Huang Y (Eds.) 2005. An Illustrated Key to Chinese Amphibians. 1153 Sichuan Publishing House of Science and Technology, Chengdu.

115Felsenstein J. 2004. Inferring Phylogenies. Vol. 2. Sunderland: Sinauer Associates, Inc., 465. 115Feng Y, Blackburn DC, Liang D, Hillis DM, Wake DB, Cannatella DC, Zhang P. 2017. 1156 Phylogenomics reveals rapid, simultaneous diversification of three major clades of Gondwanan 1157 frogs at the Cretaceous-Paleogene boundary. Proceedings of the National Academy of Sciences 1158 114:5864-5870.

115Fromhage L, Vences M, Veith M. 2004. Testing alternative vicariance scenarios in Western 1160 Mediterranean discoglossid frogs. Molecular Phylogenetics and Evolution 31(1):308-322.

116Frost DR, Grant T, Faivovich J, Bain RH, Haas A, Haddad CFB, de Sá RO, Channing A, 1162 Wilkinson M, Donnellan SC, Raxworthy CJ, Campbell JA, Blotto BL, Moler PE, Drewes 1163 RC, Nussbaum RA, Lynch JD, Green DM, Wheeler WC. 2006. The amphibian tree of life. 1164 Bulletin of the American Museum of Natural History 297:1-370.

116Frost DR. 2020. Amphibian species of the world 6.0, an online reference. (2020-01). New York: 1166 Darrel Frost and the American Museum of Natural History. Available at 1167 http://research.amnh.org/herpetology/amphibia/index.html (accessed 30 March 2020). 
116Fujisawa T, Barraclough TG. 2013. Delimiting species using single-locus data and the 1169 Generalized Mixed Yule Coalescent approach: a revised method and evaluation on simulated 1170 data sets. Systematic Biology 62:707-724.

117Fujita MK, Leaché AD, Burbrink FT, McGuire JA, Moritz C. 2012. Coalescent based species 1172 delimitation in an integrative taxonomy. Trends in Ecology and Evolution 27:480-488.

1173Garg S, Biju SD. 2019. New microhylid frog genus from Peninsular India with Southeast Asian 1174 affinity suggests multiple Cenozoic biotic exchanges between India and Eurasia. Scientific 1175 Reports 9(1):1906.

1176arg S, Suyesh R, Das A, Jiang J, Wijayathilaka N, Amarasinghe AT, Alhadi F, Vineeth KK, 1177 Aravind NA, Senevirathne G, Meegaskumbura M, Biju SD. 2019. Systematic revision of 1178 Microhyla (Microhylidae) frogs of South Asia: a molecular, morphological, and acoustic 1179 assessment. Vertebrate Zoology 69(1):1-71.

118Geissler P, Hartmann T, Ihlow F, Rödder D, Poyarkov NA, Nguyen TQ, Ziegler T, Böhme W. 1181 2015. The Lower Mekong: an insurmountable barrier to amphibians in southern Indochina?. 1182 Biological Journal of the Linnean Society 114(4):905-914.

1183Gower DJ, Kupfer A, Oommen OV, Himstedt W, Nussbaum RA, Loader SP, Presswell B, 1184 Müller H, Krishna SB, Boistel R, Wilkinson M. 2002. A molecular phylogeny of ichthyophiid 1185 caecilians (Amphibia: Gymnophiona: Ichthyophiidae): out of India or out of South East Asia?. 1186 Proceedings of the Royal Society of London, Series B: Biological Sciences. 269(1500):156311871569.

1188Grismer JL, Schulte JA, Alexander A, Wagner P, Travers SL, Buehler MD, Welton LJ, Brown 1189 RM. 2016. The Eurasian invasion: phylogenomic data reveal multiple Southeast Asian origins 1190 for Indian Dragon Lizards. BMC Evolutionary Biology 16(1):43.

119Guo ZT, Ruddiman WF, Hao QZ, Wu HB, Qiao YS, Zhu RX, Peng SZ, Wei JJ, Yuan BY, Liu 1192 TS. 2002. Onset of Asian desertification by 22Myr ago inferred from loess deposits in China. 1193 Nature 416(6877):159-163 DOI 10.1038/416159a.

1194Hall R. 2012. Late Jurassic-Cenozoic reconstructions of the Indonesian region and the Indian Ocean. 1195 Tectonophysics 570:1-41.

119đHall TA. 1999. BioEdit: a user-friendly biological sequence alignment editor and analysis program 1197 for Windows 95/98/NT. Nucleotide 41:95-98. 
119\&anken J, Wake DB. 1993. Miniaturization of body size: organismal consequences and 1199 evolutionary significance. Annual Review of Ecology and Systematics 24:501-519.

120dHanken J. 1985. Morphological novelty in the limb skeleton accompanies miniaturization in 1201 salamanders. Science 229:871-874.

120Harikrishnan S, Vasudevan K, De Silva A, Deepak V, Kar NB, Naniwadekar R, Lalremruata 1203 A, Prasoona KR, Aggarwal RK. 2012. Phylogeography of Dasia Gray, 1830 (Reptilia: 1204 Scincidae), with the description of a new species from southern India. Zootaxa 3233(1):37-51. 120צarrison TM, Copeland P, Kidd WSF, Yin A. 1992. Raising Tibet. Science 255(5052):1663-1670 1206 DOI 10.1126/science.255.5052.1663.

120Hasan M, Islam MM, Khan MMR, Alam MS, Kurabayashi A, Igawa T, Kuramoto M, Sumida 1208 M. 2012. Cryptic anuran biodiversity in Bangladesh revealed by mitochondrial 16S rRNA gene 1209 sequences. Zoological science 29(3):162-172.

1214Hasan M, Islam MM, Kuramoto M, Kurabayashi A, Sumida M. 2014a. Description of two new 1211 species of Microhyla (Anura: Microhylidae) from Bangladesh. Zootaxa 3755:401-408.

121Hasan M, Islam MM, Khan MMR, Igawa T, Alam MS, Djong HT, Kurniawan N, Joshy H, 1213 Sen YH, Belabut DM, Kurabayashi A. 2014b. Genetic divergences of South and Southeast 1214 Asian frogs: a case study of several taxa based on 16S ribosomal RNA gene data with notes on 1215 the generic name Fejervarya. Turkish Journal of Zoology 38(4):389-411.

1214Holman JA. 2003. Fossil frogs and toads of North America. In: Farlow JO (Ed.) Indiana university 1217 press. Bloomington: Indiana $246 \mathrm{pp}$.

121Howlader MSA, Nair A, Gopalan SV, Merilä J. 2015. A new species of Microhyla (Anura: 1219 Microhylidae) from Nilphamari, Bangladesh. PloS One 10(3):e0119825:1-18.

122 Huelsenbeck JP, Hillis DM. 1993. Success of phylogenetic methods in the four-taxon case. 1221 Systematic Biology 42(3):247-264 DOI 10.1093/sysbio/42.3.247.

122Huelsenbeck JP, Ronquist F. 2001. MrBayes: Bayesian inference of phylogenetic trees. 1223 Bioinformatics 17:754-755.

1224nger RF. 1989. Four new species of frogs from Borneo. Malayan Nature Journal, Kuala Lumpur 1225 42:229-243.

122đnger RF, Frogner KJ. 1979. New species of narrow-mouth frogs (genus Microhyla) from Borneo. 1227 Sarawak Museum Journal 27:311-322. 
122אamei RG, Mauro DS, Gower DJ, Van Bocxlaer I, Sherratt E, Thomas A, Babu S, Bossuyt F, 1229 Wilkinson M, Biju SD. 2012. Discovery of a new family of amphibians from northeast India 1230 with ancient links to Africa. Proceedings of the Royal Society B: Biological Sciences. 1231 279(1737):2396-2401.

123Karanth KP. 2006. Out-of-India: Gondwanan origin of some tropical Asian biota. Current Science 1233 90:789-792.

1234Karunarathna S, Poyarkov NA, de Silva A, Madawala M, Botejue M, Gorin VA, Surasinghe T, 1235 Gabadage D, Ukuwela KD, Bauer AM. 2019. Integrative taxonomy reveals six new species of 1236 day geckos of the genus Cnemaspis Strauch, 1887 (Reptilia: Squamata: Gekkonidae) from 1237 geographically isolated hill forests in Sri Lanka. Vertebrate Zoology 64:247-298.

123\%atoh K, Misawa K, Kuma K, Miyata T. 2002. MAFFT: a novel method for rapid multiple 1239 sequence alignment based on fast Fourier transform. Nucleic Acids Research 30(14):3059-3066.

124Khatiwada JR, Shu GC, Wang SH, Thapa A, Wang B, Jiang J. 2017. A new species of the genus 1241 Microhyla (Anura: Microhylidae) from Eastern Nepal. Zootaxa 4254(2):221-239.

124Klaus S, Morley RJ, Plath M, Zhang YP, Li JT. 2016. Biotic interchange between the Indian 1243 subcontinent and mainland Asia through time. Nature Communications 7:12132.

1244Klaus S, Schunart CD, Streit B, Pfenninger M. 2010. When Indian crabs were not yet Asian 1245 biogeographic evidence for Eocene proximity of India and Southeast Asia. BMC Evolutionary 1246 Biology 10:1-9.

124Köhler F, Glaubrecht M. 2007. Out of Asia and into India: on the molecular phylogeny and 1248 biogeography of the endemic freshwater gastropod Paracrostoma Cossmann, 1900 1249 (Caenogastropoda: Pachychilidae). Biological Journal of the Linnean Society 91(4):627-651.

125Kraus F. 2011. At the lower size limit for tetrapods, two new species of the miniaturized frog genus 1251 Paedophryne (Anura, Microhylidae). ZooKeys 154:71-88 DOI 10.3897/zookeys.154.1963 125Kurabayashi A, Matsui M, Belabut DM, Yong HS, Ahmad N, Sudin A, Kuramoto M, Hamidy 1253 A, Sumida M. 2011. From Antarctica or Asia? New colonization scenario for Australian-New 1254 Guinean narrow mouth toads suggested from the findings on a mysterious genus 1255 Gastrophrynoides. BMC Evolutionary Biology 11(1):175.

125Lanfear R, Calcott B, Ho SYW, Guindon S. 2012. PartitionFinder: combined selection of 1257 partitioning schemes and substitution models for phylogenetic analyses. Molecular Biology and 1258 Evolution 29(6):1695-1701 DOI 10.1093/molbev/mss020. 
1259ee KH, Shaner PJ, Lin YP, Lin SM. 2016. Geographic variation in advertisement calls of a 1260 Microhylid frog - testing the role of drift and ecology. Ecology and Evolution 6(10):3289-3298. 1261ehr E, Coloma LA. 2008. A minute new Ecuadorian Andean frog (Anura: Strabomantidae, 1262 Pristimantis). Herpetologica 64(3):354-367.

126Ieigh JW, Bryant D. 2015. Popart: full-feature software for haplotype network construction. 1264 Methods in Ecology and Evolution 6:1110-1116 DOI 10.1111/2041-210x.12410.

126Li JT, Li Y, Klaus S, Rao DQ, Hillis DM, Zhang YP. 2013. Diversification of rhacophorid frogs 1266 provides evidence for accelerated faunal exchange between India and Eurasia during the 1267 Oligocene. Proceedings of the National Academy of Sciences 110(9):3441-3446.

1268Macey JR, Kuehl JV, Larson A, Robinson MD, Ugurtas IH, Ananjeva NB, Rahman H, Javed 1269 HI, Osman RM, Doumma A, Papenfuss TJ. 2008. Socotra Island the forgotten fragment of 1270 Gondwana: Unmasking chameleon lizard history with complete mitochondrial genomic data. 1271 Molecular Phylogenetics and Evolution 49(3):1015-1018.

1272Maddison WP, Maddison DR. 2017. Mesquite: a modular system for evolutionary analysis. 1273 Version 3.31. Available at http://mesquiteproject.org.

1274Maddison WP. 1991. Squared-change parsimony reconstructions of ancestral states for continuous1275 valued characters on a phylogenetic tree. Systematic Zoology 40(3):304-314 DOI $127610.2307 / 2992324$.

127Matsui M, Hamidy A, Belabut DM, Ahmad N, Panha S, Sudin A, Khonsue W, Oh HS, Yong 1278 HS, Jiang JP, Nishikawa K. 2011. Systematic relationships of Oriental tiny frogs of the family 1279 Microhylidae (Amphibia, Anura) as revealed by mtDNA genealogy. Molecular Phylogenetics 1280 and Evolution 61(1):167-176.

1281Matsui M, Hamidy A, Eto K. 2013. Description of a new species of Microhyla from Bali, 1282 Indonesia (Amphibia, Anura). Zootaxa 3670(4):579-590.

1283atsui M, Ito H, Shimada T, Ota H, Saidapur SK, Khonsue W, Tanaka-Ueno T, Wu GF. 2005. 1284 Taxonomic relationships within the pan-oriental narrowmouth toad Microhyla ornata as revealed 1285 by mtDNA analysis (Amphibia, Anura, Microhylidae). Zoological Science 22(4):489-495.

1286atsui M. 2011. Taxonomic revision of one of the Old World's smallest frogs, with description of a 1287 new Bornean Microhyla (Amphibia, Microhylidae). Zootaxa 2814(1):33-49. 
1288Matzke NJ. 2013. Probabilistic historical biogeography: new models for founder-event speciation, 1289 imperfect detection, and fossils allow improved accuracy and model-testing. Frontiers of 1290 Biogeography 5(4).

129Molnar P. 2005. Mio-Pliocene growth of the Tibetan Plateau and evolution of East Asian climate. 1292 Palaeontologia Electronica 8(1):1-23.

1293Morley RJ. 2000. Origin and evolution of tropical rain forests, Wiley, Chichester 362 pp.

1294Morley RJ. 2018. Assembly and division of the South and South-east Asian flora in relation to 1295 tectonics and climate change. Journal of Tropical Ecology 34(4):209-234.

1296Mulcahy DG, Lee JL, Miller AH, Chand M, Thura MK, Zug GR. 2018. Filling the BINs of life: 1297 Report of an amphibian and reptile survey of the Tanintharyi (Tenasserim) Region of Myanmar, 1298 with DNA barcode data. ZooKeys 757:85-152.

1299Mers N, Mittermeier RA, Mittermeier CG, Da Fonseca GA, Kent J. 2000. Biodiversity 1300 hotspots for conservation priorities. Nature 403(6772):853.

130Nguyen LT, Poyarkov NA, Nguyen TT, Nguyen TA, Tran VH, Gorin VA, Murphy RW, 1302 Nguyen SN. 2019. A new species of the genus Microhyla Tschudi, 1838 (Amphibia: Anura: 1303 Microhylidae) from Tay Nguyen Plateau, Central Vietnam. Zootaxa 4543:549-580.

1304Nguyen LT, Schmidt HA, Von Haeseler A, Minh BQ. 2015. IQ-TREE: a fast and effective 1305 stochastic algorithm for estimating maximum-likelihood phylogenies. Molecular Biology and 1306 Evolution 32(1):268-274.

130Nguyen TV, Duong TV, Luu KT, Poyarkov NA. 2020. A new species of Kurixalus (Anura: 1308 Rhacophoridae) from northern Vietnam with comments on the biogeography of the genus. 1309 Journal of Natural History in press DOI 10.1080/00222933.2020.1728411

131 Oliver PM, Iannella A, Richards SJ, Lee MSY. 2017. Mountain colonisation, miniaturisation and 1311 ecological evolution in a radiation of direct-developing New Guinea frogs (Choerophryne, 1312 Microhylidae). PeerJ 5:e3077. DOI 10.7717/peerj.3077

13130ta H. 1998. Geographic patterns of endemism and speciation in amphibians and reptiles of the 1314 Ryukyu Archipelago, Japan, with special reference to their paleogeographic implications. 1315 Researches on Population Ecology 40:189-204.

131Parker HW. 1928. The brevicipitid frogs of the genus Microhyla. Annals and Magazine of Natural 1317 History, Series 10 2:473-499. 
1319arker HW. 1934. A Monograph of the Frogs of the Family Microhylidae. British Museum 1319 (Natural History), London, (1) + viii + 208 pp.

132 Parra-Olea G, Rovito SM, García-París M, Maisano JA, Wake DB, Hanken J. 2016. Biology of 1321 tiny animals: three new species of minute salamanders (Plethodontidae: Thorius) from Oaxaca, 1322 Mexico. PeerJ 4:e2694.

132Peloso PL, Frost DR, Richards SJ, Rodrigues MT, Donnellan S, Matsui M, Raxworthy CJ, 1324 Biju SD, Lemmon EM, Lemmon AR, Wheeler WC. 2016. The impact of anchored 1325 phylogenomics and taxon sampling on phylogenetic inference in narrow-mouthed frogs (Anura, 1326 Microhylidae). Cladistics 32(2):113-140.

132 Polilov AA. 2015. Small is beautiful: features of the smallest insects and limits to miniaturization. 1328 Annual Review of Entomology 60:103-121.

1329ons J, Barraclough TG, Gomez-Zurita J, Cardoso A, Duran DP, Hazell S, Kamoun S, Sumlin, 1330 WD, Vogler AP. 2006. Sequence-based species delimitation for the DNA taxonomy of 1331 undescribed insects. Systematic Biology 55:595-609.

133Poyarkov NA, Gorin VA, Zaw T, Kretova VD, Gogoleva SI, Pawangkhanant P, Che J. 2019. 1333 On the road to Mandalay: contribution to the Microhyla Tschudi, 1838 (Amphibia: Anura: 1334 Microhylidae) fauna of Myanmar with description of two new species. Zoological Research 1335 40(4):244-276 DOI 10.24272/j.issn.2095-8137.2019.044.

133Poyarkov NA, Nguyen TV, Duong TV, Gorin VA, Yang JH. 2018a. A new limestone-dwelling 1337 species of Micryletta (Amphibia: Anura: Microhylidae) from northern Vietnam. PeerJ 6:e5771 1338 DOI 10.7717/peerj.5771

1339oyarkov NA, Suwannapoom C, Pawangkhanant P, Aksornneam A, Duong TV, Korost DV, 1340 Che J. 2018b. A new genus and three new species of miniaturized microhylid frogs from 1341 Indochina (Amphibia: Anura: Microhylidae: Asterophryinae). Zoological Research 39(3):1301342155.

134Poyarkov NA, Vassilieva AB, Orlov NL, Galoyan EA, Tran DTA, Le DTT, Kretova VD, 1344 Geissler P. 2014. Taxonomy and distribution of narrow-mouth frogs of the genus Microhyla 1345 Tschudi, 1838 (Anura: Microhylidae) from Vietnam with descriptions of five new species. 1346 Russian Journal of Herpetology 21:89-148.

134Puillandre N, Lambert A, Brouillet S, Achaz G. 2012. ABGD, Automatic Barcode Gap Discovery 1348 for primary species delimitation. Molecular Ecology 21:1864-1877. 
134Pyron RA, Kandambi HKD, Hendry CR, Pushpamal V, Burbrink FT, Somaweera R. 2013. 1350 Genus-level molecular phylogeny of snakes reveals the origins of species richness in Sri Lanka. 1351 Molecular Phylogenetics and Evolution 66:969-975 DOI 10.1016/j.ympev.2012.12.004 135Rakotoarison A, Scherz MD, Glaw F, Köhler J, Andreone F, Franzen M, Glos J, Hawlitschek 1353 O, Jono T, Mori A, Ndriantsoa SH. 2017. Describing the smaller majority: integrative 1354 taxonomy reveals twenty-six new species of tiny microhylid frogs (genus Stumpffia) from 1355 Madagascar. Vertebrate Zoology 67(3):271-398.

135Rambaut A, Drummond AJ. 2007. Tracer v1. 5. Available at http://beast.bio.ed.ac.uk/Tracer. 135Raxworthy CJ, Forstner MRJ, Nussbaum RA. 2002. Chameleon radiation by oceanic dispersal. 1358 Nature 415:784-787.

135Ree RH, Moore BR, Webb CO, Donoghue MJ. 2005. A likelihood framework for inferring the 1360 evolution of geographic range on phylogenetic trees. Evolution 59(11):2299-2311 DOI 1361 10.1111/j.0014-3820.2005.tb00940.x.

136Ree RH, Smith SA. 2008. Maximum likelihood inference of geographic range evolution by 1363 dispersal, local extinction, and cladogenesis. Systematic Biology 57(1):4-14 DOI $136410.1080 / 10635150701883881$.

136Reid NM, Carstens BC. 2012. Phylogenetic estimation error can decrease the accuracy of species 1366 delimitation: a Bayesian implementation of the general mixed Yule-coalescent model. BMC 1367 Evolutionary Biology 12:196.

136Renner SS. 2004. Tropical trans-Atlantic disjunctions, sea surface currents, and wind patterns. 1369 International Journal of Plant Sciences 165:23-33.

137Rieppel O. 1996. Miniaturization in tetrapods: consequences for skull morphology. Symposia of the 1371 Zoological Society of London 69:47-61.

137Rittmeyer EN, Allison A, Grundler MC, Thompson DK, Austin CC. 2012. Ecological guild 1373 evolution and the discovery of the world's smallest vertebrate. PloS One 7(1):e29797. DOI 1374 10.1371/journal.pone.0029797

137Roelants K, Jiang J, Bossuyt F. 2004. Endemic ranid (Amphibia: Anura) genera in southern 1376 mountain ranges of the Indian subcontinent represent ancient frog lineages: Evidence from 1377 molecular data. Molecular Phylogenetics and Evolution 31(2):730-740.

137Ronquist F, Huelsenbeck JP. 2003. MrBayes 3: Bayesian phylogenetic inference under mixed 1379 models. Bioinformatics 19(12):1572-1574 DOI 10.1093/bioinformatics/btg180. 
138Ronquist F. 1997. Dispersal-vicariance analysis: a new approach to the quantification of historical 1381 biogeography. Systematic Biology 46:195-203.

138Rovito SM, Parra-Olea G, Hanken J, Bonett RM, Wake DB. 2013. Adaptive radiation in 1383 miniature: the minute salamanders of the Mexican highlands (Amphibia: Plethodontidae: 1384 Thorius). Biological Journal of the Linnean Society 109:622-643.

138Russell DW, Sambrook J. 2001. Molecular cloning: a laboratory manual. Cold Spring Harbor, 1386 NY: Cold Spring Harbor Laboratory.

138Sanchiz B. 1998. Encyclopedia of paleoherpetology. Part 4. Salientia. München: Pfeil 275 pp. 138\$avage JM. 1973. The geographic distribution of frogs: patterns and predictions: In: Evolutionary 1389 biology of the anurans. University of Missouri Press, Missouri: 351-445.

139Scherz MD, Hutter CR, Rakotoarison A, Riemann JC, Rödel MO, Ndriantsoa SH, Glos J, 1391 Roberts SH, Crottini A, Vences M, Glaw F. 2019. Morphological and ecological convergence 1392 at the lower size limit for vertebrates highlighted by five new miniaturised microhylid frog 1393 species from three different Madagascan genera. PloS One 14(3).

1394eshadri KS, Singal R, Priti H, Ravikanth G, Vidisha MK, Saurabh S, Pratik M, Gururaja KV. 1395 2016. Microhyla laterite sp. nov., a new species of Microhyla Tschudi, 1838 (Amphibia: Anura: 1396 Microhylidae) from a laterite rock formation in South West India. PloS One 11(3):e0149727. 139Solovyeva EN, Lebedev VS, Dunayev EA, Nazarov RA, Bannikova AA, Che J, Murphy RW, 1398 Poyarkov NA. 2018. Cenozoic aridization in Central Eurasia shaped diversification of toad1399 headed agamas (Phrynocephalus; Agamidae, Reptilia). PeerJ 6:e4543 DOI 10.7717/peerj.4543 140Sparks JS. 2003. Molecular phylogeny and biogeography of the Malagasy and South Asian cichlids 1401 (Teleostei: Perciformis: Cichlidae). Molecular Phylogenetics and Evolution 30:599-614.

140Streicher JW, Loader SP, Varela-Jaramillo A, Montoya P, de Sá RO. 2020. Analysis of 1403 ultraconserved elements supports African origins of narrow-mouthed frogs. Molecular 1404 Phylogenetics and Evolution 146:106771 DOI 10.1016/j.ympev.2020.106771

140Stuart SN (Ed.). 2008. Threatened amphibians of the world. Lynx Edicions, Barcelona, Spain. 776 1406 pp.

140Suwannapoom C, Sumontha M, Tunprasert J, Ruangsuwan T, Pawangkhanant P, Korost DV, 1408 Poyarkov NA. 2018. A striking new genus and species of cave-dwelling frog (Amphibia: Anura: 1409 Microhylidae: Asterophryinae) from Thailand. PeerJ 6:e4422 DOI 10.7717/peerj.4422 
1410Tamura K, Stecher G, Peterson D, Filipski A, Kumar S. 2013. MEGA6: molecular evolutionary 1411 genetics analysis version 6.0. Molecular Biology and Evolution 30(12):2725-2729.

1412Tominaga A, Matsui M, Shimoji N, Khonsue W, Wu CS, Toda M, Eto K, Nishikawa K, Ota H. 1413 2019. Relict distribution of Microhyla (Amphibia: Microhylidae) in the Ryukyu Archipelago: 1414 High diversity in East Asia maintained by insularization. Zoologica Scripta 48(4):440-453.

1415Tracy CR, Christian KA, Tracy CR. 2010. Not just small, wet, and cold: effects of body size and 1416 skin resistance on thermoregulation and arboreality of frogs. Ecology 91(5):1477-1484. DOI $1417 \quad 10.1890 / 09-0839.1$

1418Tu N, Yang M-H, Liang D, Zhang P. 2018. A large-scale phylogeny of Microhylidae inferred from 1419 a combined dataset of 121 genes and 427 taxa. Molecular Phylogenetics and Evolution 126:85142091.

1421Turner H, Hovenkamp P, Van Welzen PC. 2001. Biogeography of Southeast Asia and the West 1422 Pacific. Journal of Biogeography 28:217-230.

1423 an Bocxlaer I, Roelants K, Biju SD, Nagaraju J, Bossuyt F. 2006. Late Cretaceous vicariance in 1424 Gondwanan amphibians. PloS One 1(1):e74.

1425 Van der Meijden A, Vences M, Hoegg S, Boistel R, Channing A, Meyer A. 2007. Nuclear gene 1426 phylogeny of narrow-mouthed toads (Family: Microhylidae) and a discussion of competing 1427 hypotheses concerning their biogeographical origins. Molecular Phylogenetics and Evolution 1428 44:1017-1030.

1429 Van Hinsbergen DJ, Kapp P, Dupont - Nivet G, Lippert PC, DeCelles PG, Torsvik TH. 2011. 1430 Restoration of Cenozoic deformation in Asia and the size of Greater India. Tectonics 30(5): 1431 TC5003.

1432 an Hinsbergen DJ, Lippert PC, Dupont-Nivet G, McQuarrie N, Doubrovine PV, Spakman W, 1433 Torsvik TH. 2012. Greater India Basin hypothesis and a two-stage Cenozoic collision between 1434 India and Asia. Proceedings of the National Academy of Sciences 109(20):7659-7664.

1435 assilieva AB, Trounov VL, Poyarkov NA, Galoyan EA. 2017. The phytotelm tadpoles of 1436 Microhyla arboricola (Anura: Microhylidae) from Vietnam, with comments on reproductive 1437 biology and development. Zootaxa 4247(4):413-428.

1438/ences M, Thomas M, Bonett RM, Vieites DR. 2005. Deciphering amphibian diversity through 1439 DNA barcoding: chances and challenges. Philosophical Transactions of the Royal Society of 1440 London Series B: Biological Sciences 360(1462): 1859-1868. 
144Nences M, Vieites DR, Glaw F, Brinkmann H, Kosuch J, Veith M, Meyer A. 2003. Multiple 1442 overseas dispersal in amphibians. Proceedings of the Royal Society of London Series B: 1443 Biological Sciences. 270(1532):2435-2442.

1444ieites DR, Wollenberg KC, Andreone F, Köhler J, Glaw F, Vences M. 2009. Vast 1445 underestimation of Madagascar's biodiversity evidenced by an integrative amphibian inventory. 1446 Proceedings of the National Academy of Sciences 106(20):8267-8272.

144Xineeth KK, Radhakrishna UK, Godwin RD, Anwesha S, Rajashekhar KP, Aravind NA. 2018. 1448 A new species of Microhyla Tschudi, 1838 (Anura: Microhylidae) from West Coast of India: an 1449 integrative taxonomic approach. Zootaxa 4420:151-179.

145WWang YH, Hsiao YW, Lee KH, Tseng HY, Lin YP, Komaki S, Lin SM. 2017. Acoustic 1451 differentiation and behavioral response reveals cryptic species within Buergeria treefrogs (Anura, 1452 Rhacophoridae) from Taiwan. PloS One 12(9).

1453ijayathilaka N, Garg S, Senevirathne G, Karunarathna N, Biju S, Meegaskumbura M. 2016. 1454 A new species of Microhyla (Anura: Microhylidae) from Sri Lanka: an integrative taxonomic 1455 approach. Zootaxa 4066(3): 331-342.

1456Wilkinson M, Sheps J, Oommen OV, Cohen BL. 2002. Phylogenetic relationships of Indian 1457 caecilians (Amphibia: Gymnophiona) inferred from mitochondrial rRNA gene sequences. 1458 Molecular Phylogenetics and Evolution 23(3):401-407.

1459Wogan GOU, Vindum JV, Wilkinson JA, Koo MS, Slowinski JB, Win H, Thin T, Kyi SW, Oo 1460 SL, Lwin KS, Shein AK. 2008. New country records and range extensions for Myanmar 1461 amphibians and reptiles. Hamadryad 33:83-96.

1462Wood PL, Heinicke MP, Jackman TR, Bauer AM. 2012. Phylogeny of bent-toed geckos 1463 (Cyrtodactylus) reveals a west to east pattern of diversification. Molecular Phylogenetics and 1464 Evolution 65(3):992-1003.

1465Woodruff DS. 2010. Biogeography and conservation in Southeast Asia: how 2.7 million years of 1466 repeated environmental fluctuations affect today's patterns and the future of the remaining 1467 refugial-phase biodiversity. Biodiversity and Conservation 19(4):919-941.

1468 ang Z. 2007. PAML 4: phylogenetic analysis by maximum likelihood. Molecular Biology and 1469 Evolution 24(8):1586-1591 DOI 10.1093/molbev/msm088.

1470 You CW, Poyarkov NA, Lin SM. 2015. Diversity of the snail-eating snakes Pareas (Serpentes, 1471 Pareatidae) from Taiwan. Zoologica Scripta 44(4):349-361. 
147Хu Y, Harris AJ, Blair C, He X. 2015. RASP (Reconstruct Ancestral State in Phylogenies): a tool 1473 for historical biogeography. Molecular Phylogenetics and Evolution 87:46-49. 1474 uan ZY, Suwannapoom C, Yan F, Poyarkov NA, Nguyen SN, Chen HM, Chomdej S, 1475 Murphy RW, Che J. 2016. Red River barrier and Pleistocene climatic fluctuations shaped the 1476 genetic structure of Microhyla fissipes complex (Anura: Microhylidae) in southern China and 1477 Indochina. Current Zoology 62(6):531-543.

147\&wickl DJ, Hillis DM. 2002. Increased taxon sampling greatly reduces phylogenetic error. 1479 Systematic Biology 51:588-598. DOI 10.1080/10635150290102339 


\section{Figure 1}

Distribution and species richness of Oriental tiny frogs of the genus Microhyla.

Heatmap indicates approximate number of sympatrically co-occurring species (from 1 to 9); the highest species richness is observed in southern Vietnam and Malayan Peninsula. The individual species geographic range maps were adopted from the AmphibiaWeb (2020) database, and modified based on expert estimations in CorelDraw Graphics Suite X8. Grey / white dashed lines mark international borders on land / water, respectively. Base Map created using simplemappr.net. Photo shows Microhyla heymonsi - a widespread species occurring in Southeast and East Asia (by Nikolay A. Poyarkov).

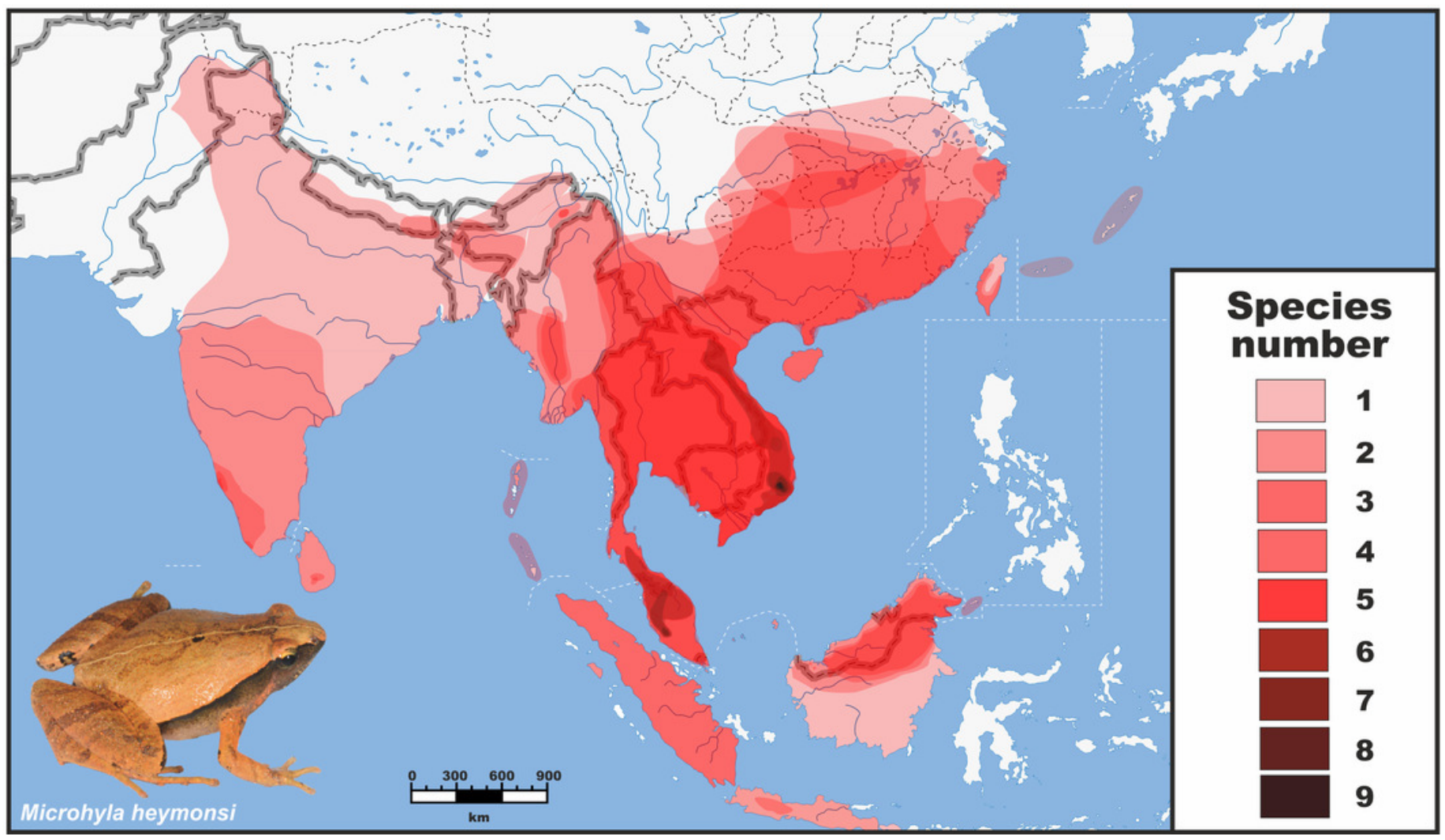




\section{Figure 2}

Biogeographic history of Microhyla.

A - Biogeographic regions used in the present study; B - BEAST chronogram on the base of $3207 \mathrm{bp}$-long mtDNA+nuDNA dataset with the results of ancestral area reconstruction in RASP. For biogeographic areas definitions, species occurrence data and transition matrices see Supplemental Information 1 and Tables S5-S6. Information at tree tips corresponds to biogeographic area code (see Fig. 2A), sample number (summarized in Supplementary Table S1), and species name, respectively. Node colors correspond to the respective biogeographic areas; values inside node icons correspond to node numbers (see Fig. S3 and Table S11 for divergence time estimates); values near nodes indicate marginal probabilities for ancestral ranges (S-DIVA analysis); icons illustrate vicariant and dispersal events (see Legend). Red arrows from 1 to 5 correspond to the dispersals to the Indian Subcontinent by Microhyla II lineages. Base Map created using simplemappr.net. 


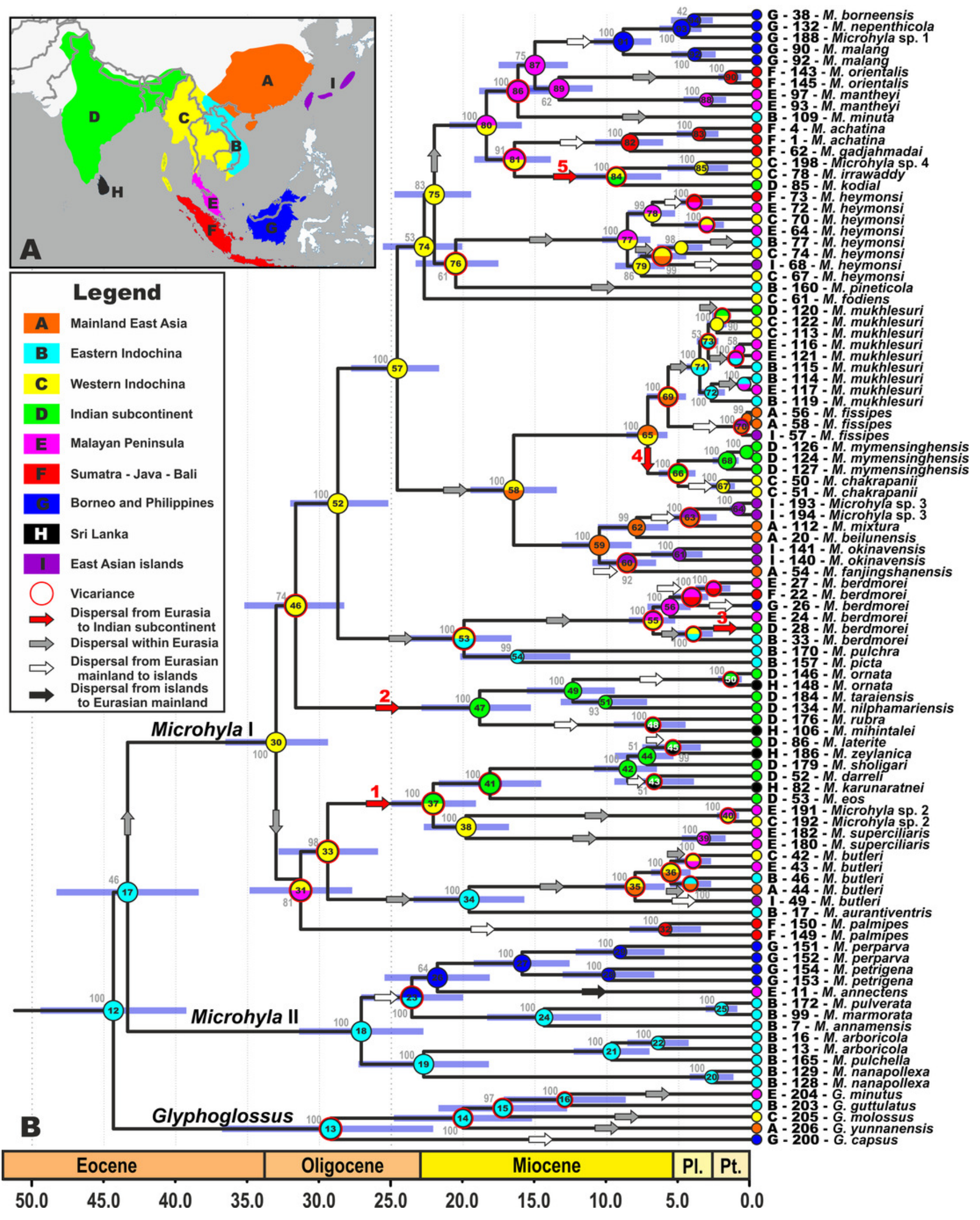




\section{Figure 3}

Paleogeography and climate of South and Southeast Asia, 60-25 Ma.

Tectonic reconstructions modified from Hall (2012); paleoclimate reconstructions based on Morley (2018). Solid arrows indicate directions of plant dispersals (dark-green - perhumid floral elements, light-green - seasonal wet / seasonal dry elements) (from Morley, 2018); red arrows show probable areas of Microhylinae diversification and ways of their dispersal. A $\mathrm{K} / \mathrm{T}$ boundary to early Paleocene: the isolated Indian subcontinent (ISC) is drifting northwards cradling perhumid tropical biota, Southeast Asia (SEA) has primarily seasonal wet or seasonal dry climate, no land connection between SEA and ISC, basal radiation of Microhylinae in the ISC; B - Paleocene to early Eocene: the ISC and SEA are at the same latitude within same perhumid climate zone, first land connections between India and Sundaland via Incertus Arc, dispersal of Microhylinae from the ISC to SEA; C - Middle Eocene: land connection between the ISC and mainland Southeast Asia (modern-day Myanmar), basal radiation of Microhyla Glyphoglossus assemblage in SEA; D - Oligocene: India drifts into northern high-pressure zone and seasonally dry climates predominate across the ISC and SEA, Microhyla II lineages colonize the ISC from SEA. Base Map created using simplemappr.net. 

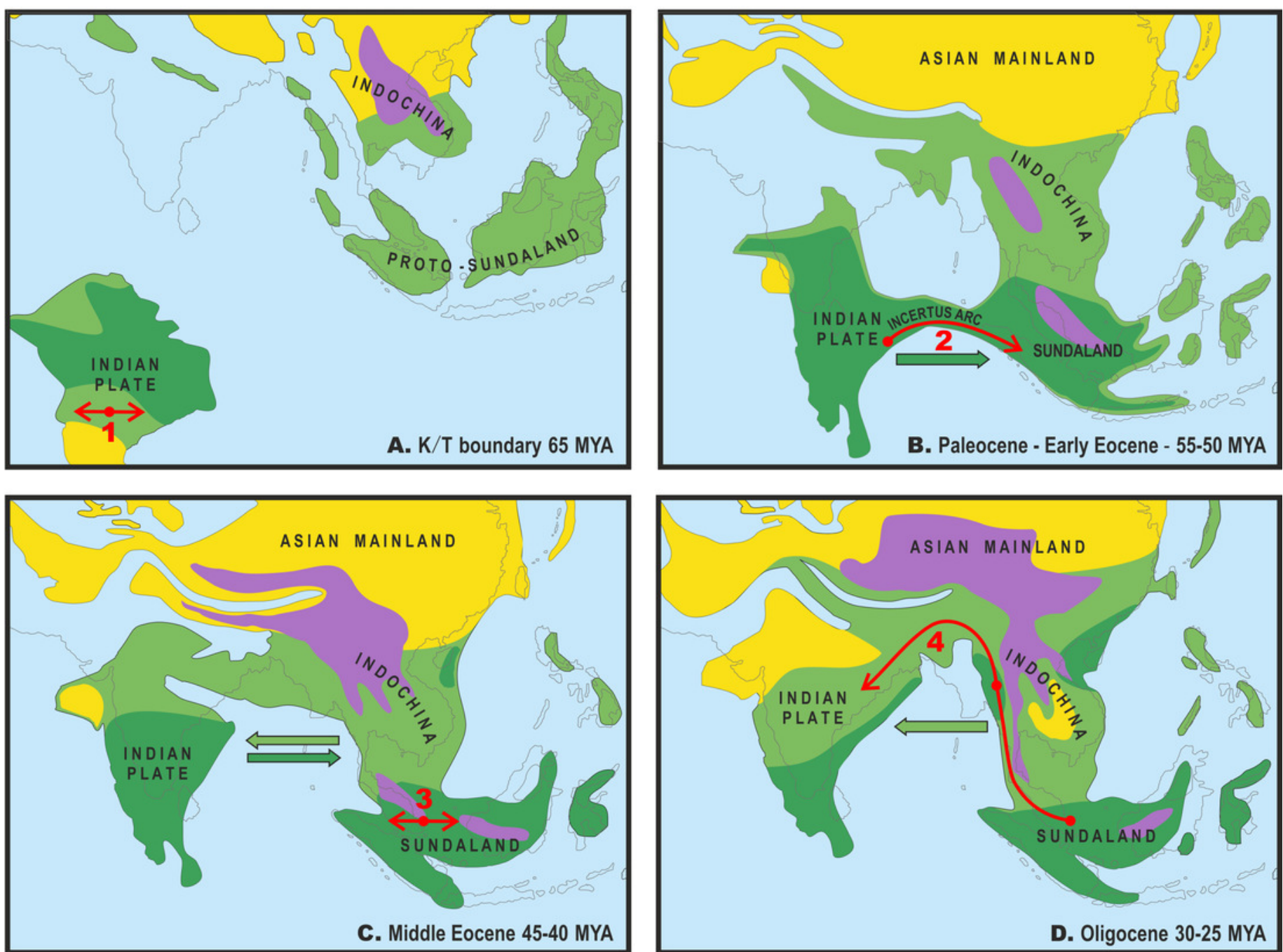

Montane climate

Seasonal wet climate

Plant dispersals

Perhumid climate

Seasonal dry climate

$\longmapsto$ Microhylid dispersals and differentiation 


\section{Figure 4}

Updated mtDNA-genealogy of the Microhyla - Glyphoglossus assemblage (full tree, part 1).

BI genealogy of Microhyla and Glyphoglossus samples examined in this study reconstructed from 2478 bp of mtDNA fragment. Values at nodes correspond to BI PP/ML BS, respectively; numbers at tips correspond to sample numbers summarized in Supplementary Table S1. Colors and letters (A-I) correspond to species groups of the Microhyla - Glyphoglossus assemblage. Yellow and red bars present the results of species delimitation analyses from bGMYC and ABGD algorithms, respectively. Frog photos are given in one scale, scale bar corresponds to $10 \mathrm{~mm}$, numbers near thumbnails correspond to species: 1 - Microhyla nepenthicola; 2 - M. borneensis; 3 - M. malang; 4 - M. orientalis; 5 - M. mantheyi; 6 - M. minuta; 7 - M. achatina; 8 - M. irrawaddy; 9 - M. heymonsi; 10 - M. pineticola; 11 - M. fodiens; 12 - M. fissipes; 13 - M. mukhlesuri; 14 - M. chakrapanii; 15 - M. okinavensis; 16 - M. berdmorei (Vietnam); 17 - M. berdmorei (Malaysia); 18 - M. picta; 19 - M. pulchra; 20 - M. zeylanica; 21 - M. sholigari; 22 - M. karunaratnei; 23 - Microhyla sp. 2; 24 - M. ornata; 25 M. mihintalei; 26 - M. butleri; 27 - M. aurantiventris; 28 - M. palmipes; 29 - M. annamensis; 30 - M. marmorata; 31 - M. pulverata; 32 - M. annectens; 33 - M. petrigena; 34 - M. perparva; 35 - M. pulchella; 36 - M. arboricola; 37 - Glyphoglossus molossus; 38 - G. guttulatus. Photos by Nikolay A. Poyarkov, Indraneil Das, Vladislav A. Gorin, Parinya Pawangkhanant, Luan Thanh Nguyen, and Evgeniya N. Solovyeva. 


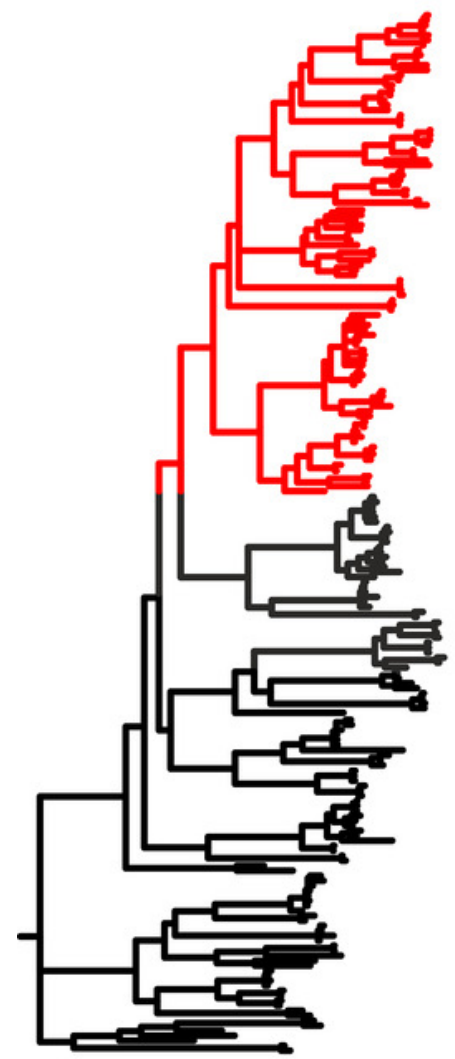

Part 1

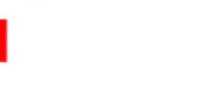

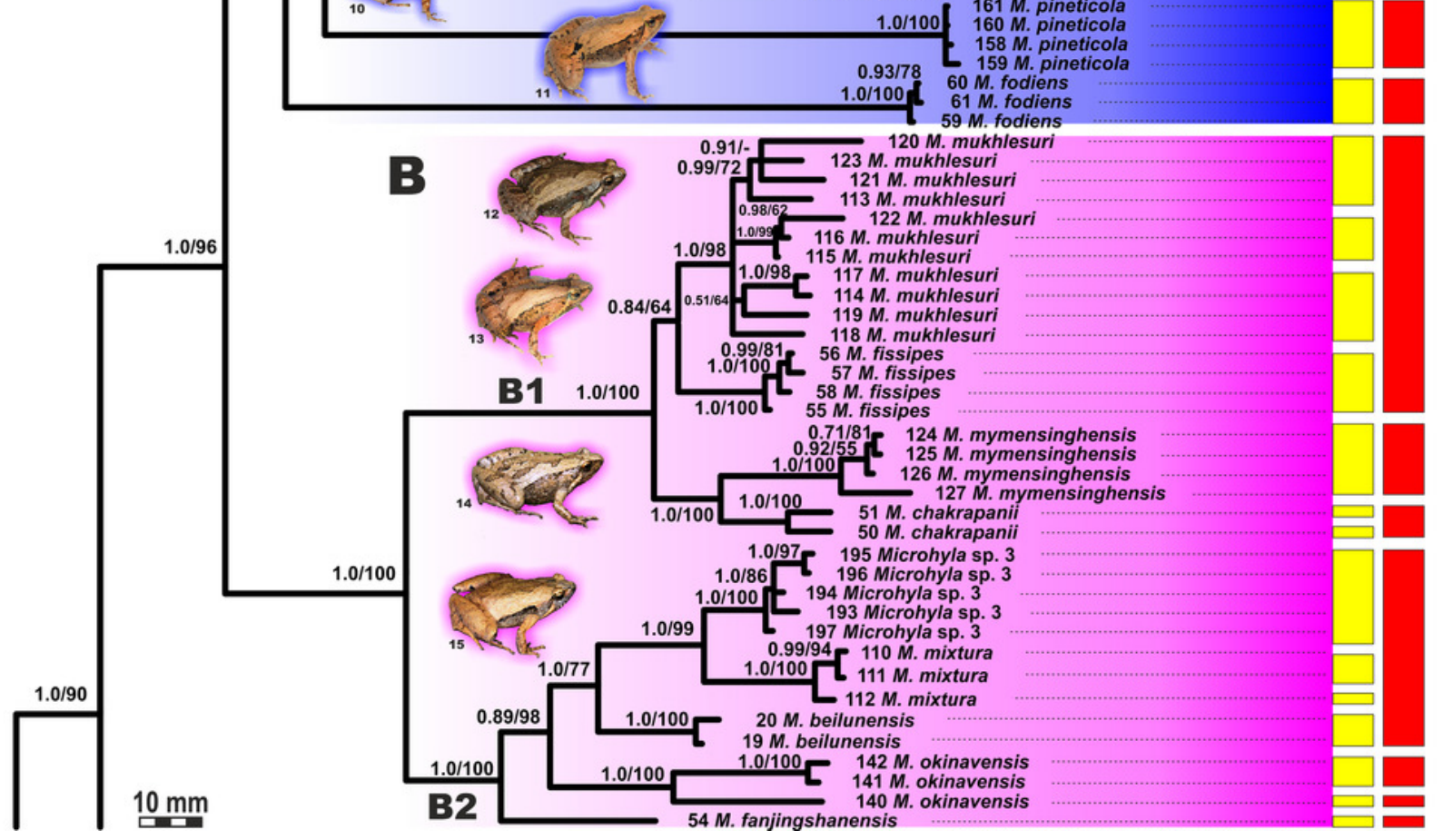




\section{Figure 5}

Updated mtDNA-genealogy of the Microhyla - Glyphoglossus assemblage (full tree, part 2).

BI genealogy of Microhyla and Glyphoglossus samples examined in this study reconstructed from 2478 bp of mtDNA fragment. Values at nodes correspond to BI PP/ML BS, respectively; numbers at tips correspond to sample numbers summarized in Supplementary Table S1. For legend, see Fig. 4. Photos by Nikolay A. Poyarkov, Indraneil Das, Vladislav A. Gorin, Parinya Pawangkhanant, Luan Thanh Nguyen, and Evgeniya N. Solovyeva. 


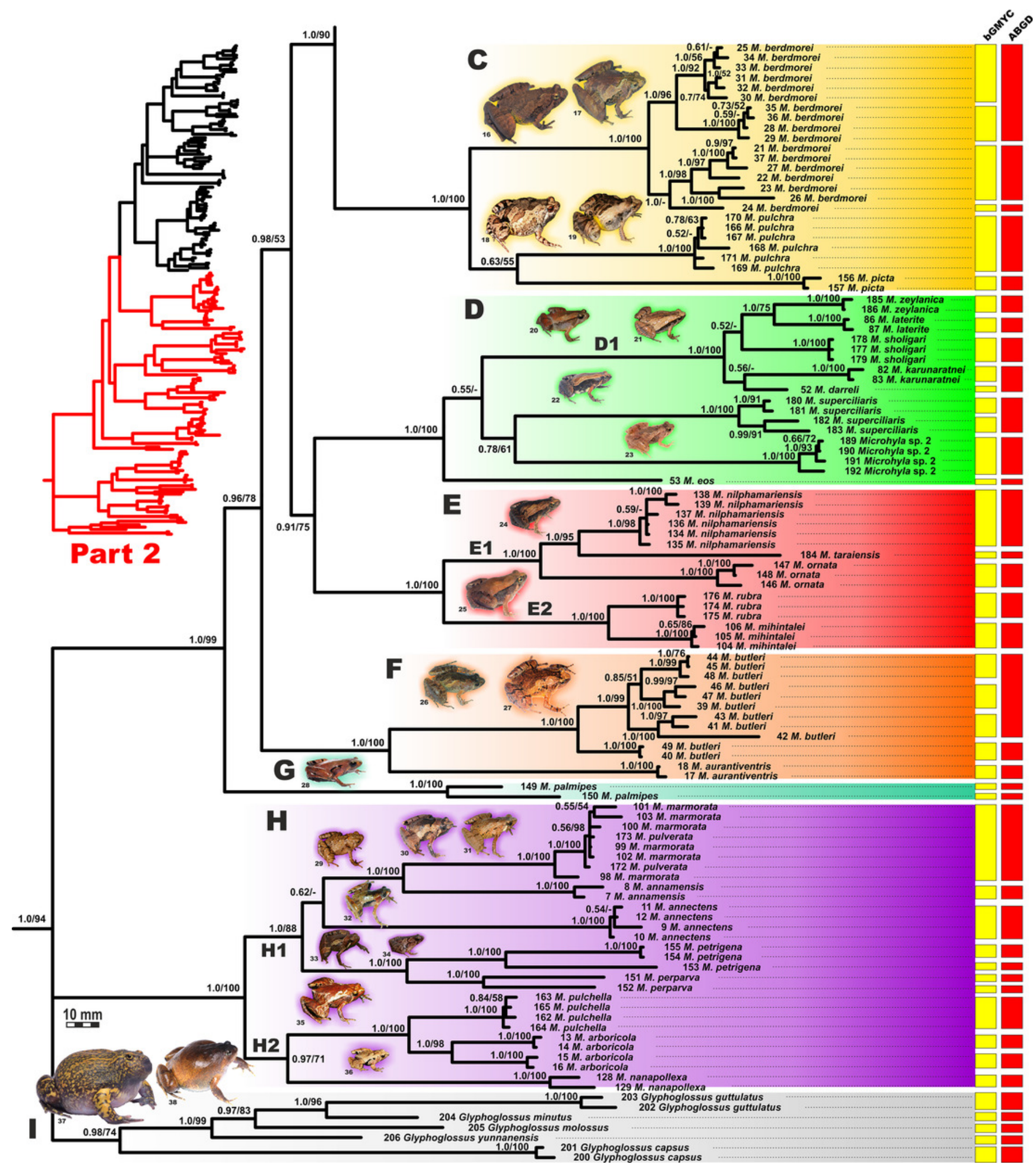




\section{Figure 6}

Maximum Likelihood tree for the "total evidence" analysis of the 3207 bp-long concatenated mtDNA + nuclear DNA dataset.

Values at nodes correspond to BEAST PP / ML BS / BI PP, respectively; black and white circles correspond to well-supported (BI PP $\geq 0.95 ; \mathrm{ML} \mathrm{BS} \geq 90$ ) and moderately supported (0.95 > $B I P P \geq 0.90 ; 90>M L B S \geq 75$ ) nodes, respectively; no circles indicate unsupported nodes. Color marking of species groups in Microhyla species complex corresponds to Figs. 4-5, but not to Fig. 2. For legend, see Fig. 4. Photos by Nikolay A. Poyarkov, Indraneil Das, Vladislav A. Gorin, Parinya Pawangkhanant, Luan Thanh Nguyen, and Evgeniya N. Solovyeva. 


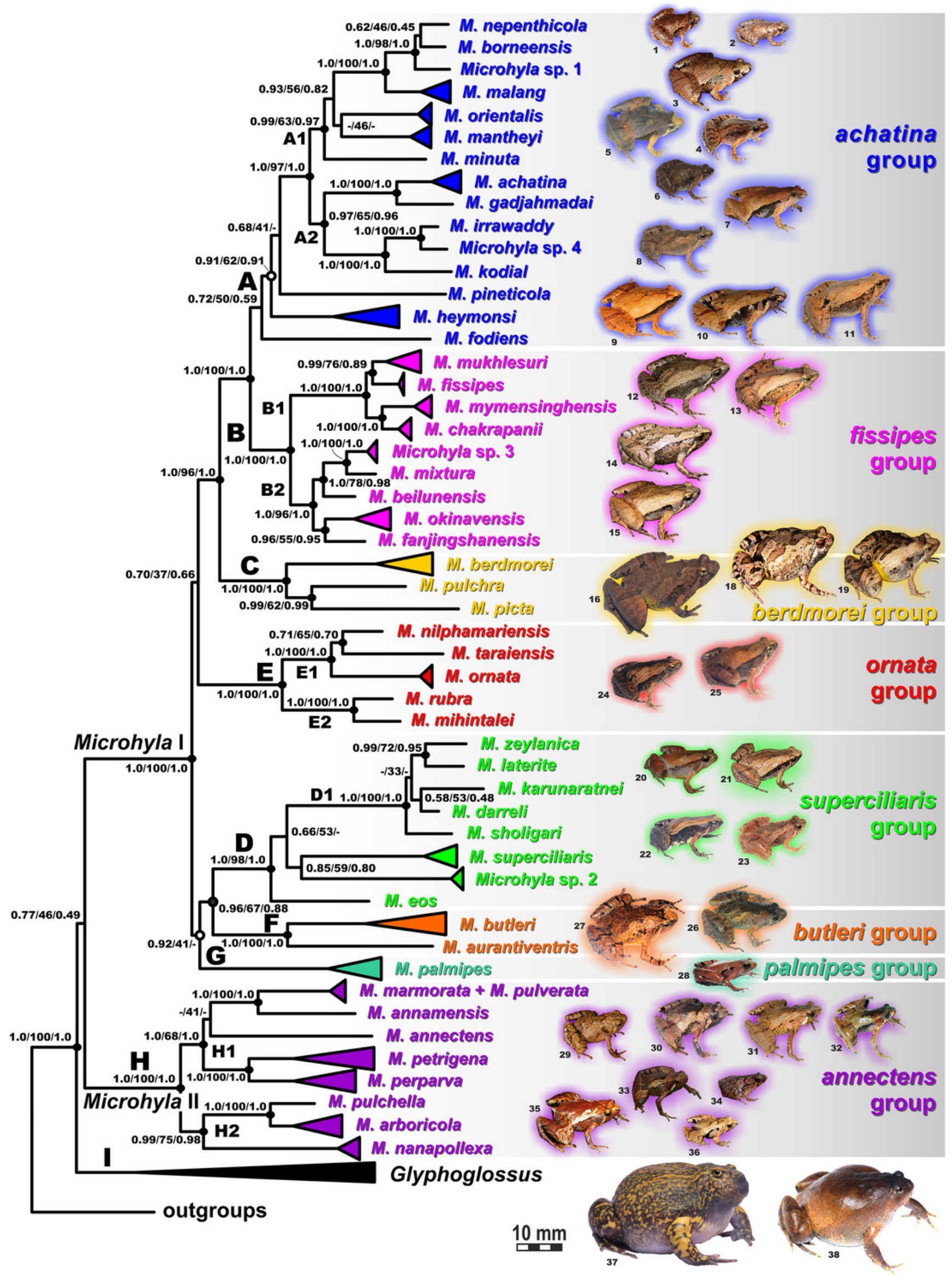




\section{Figure 7}

Body size evolution among members of the Microhyla - Glyphoglossus assemblage.

See Table S7 for SVL data. Color of branches corresponds to average SVL in males (A) and females (B) (see legend).

\section{A. Males}

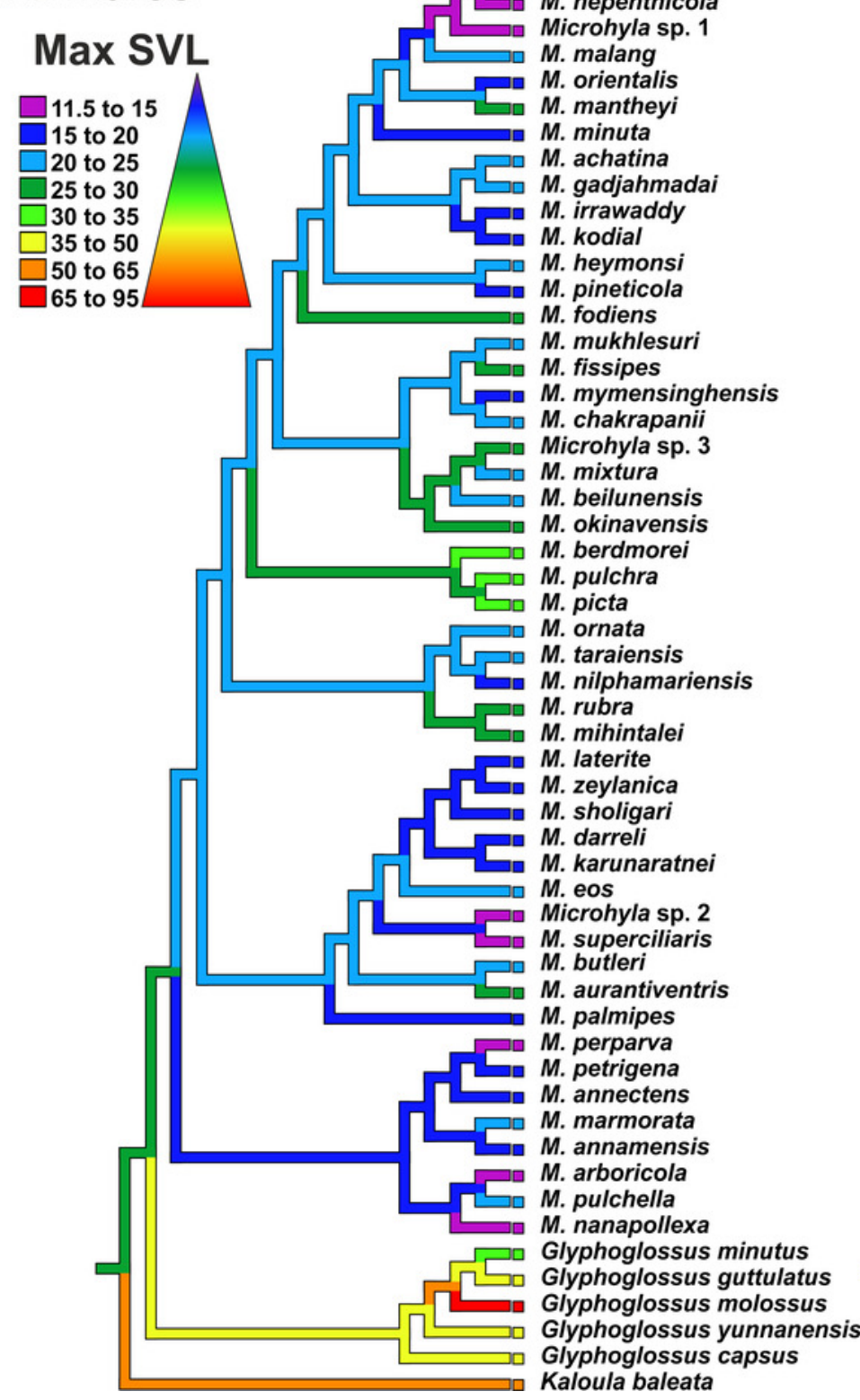

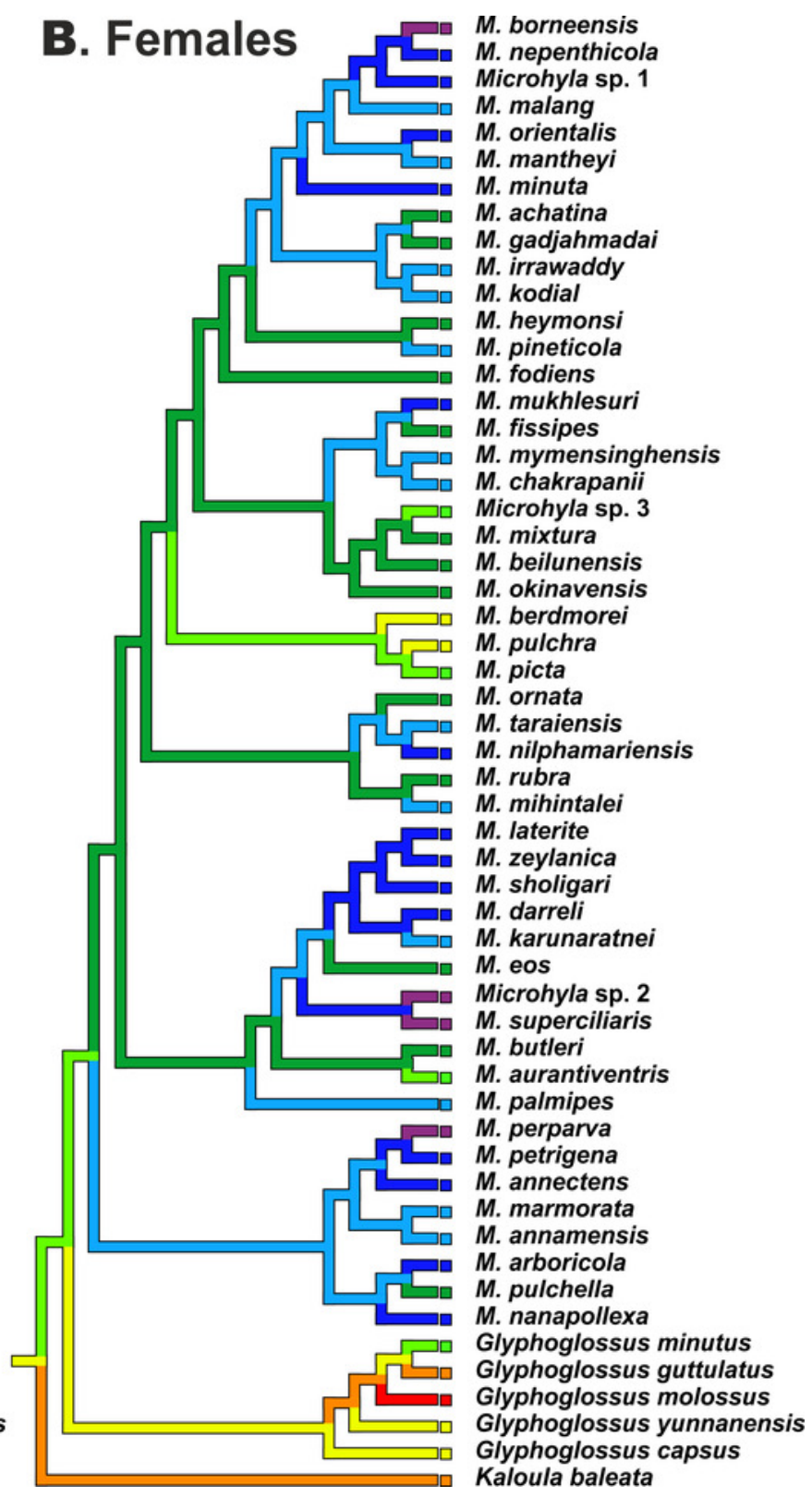

